\title{
The origins of the Selden map of China: scientific analysis of the painting materials and techniques using a holistic approach
}

\author{
Sotiria Kogou', Sarah Neate ${ }^{2,3}$, Clare Coveney ${ }^{4}$, Amanda Miles $^{4}$, David Boocock ${ }^{4}$, Lucia Burgio ${ }^{5}$, \\ Chi Shing Cheung ${ }^{1}$ and Haida Liang ${ }^{1 *}$ (D)
}

\begin{abstract}
Since the 'rediscovery' of the Selden map of China, an early seventeenth century map of Asia, in the Bodleian Library in Oxford, the importance of the map in our understanding of globalisation in the early seventeenth century has been recognised. One of the unresolved questions is the origin of the map. This paper addresses the question through material evidence provided by a holistic approach using a suite of complementary analytical techniques. The map was examined in situ and non-invasively by a remote spectral imaging instrument (PRISMS) modified for close range imaging, which was followed by a range of complementary techniques applied to a number of detached fragments, though most of the techniques are non-invasive and can be applied to the map directly in the future. The binding medium was found to be a gum, almost certainly gum Arabic, rather than the animal glue commonly used in Chinese paintings. Some of the pigments and their usage were found to be at odds with the common practice in paintings from China. The detection of gum Arabic, a binding medium used by the Europeans, South and West Asians and the use of a mixture of orpiment and indigo, commonly found in European, South and West Asian paintings gives further evidence on the unusual origins of this map. The likely detection of a basic copper chloride, such as atacamite, in the green areas suggests an influence from the South and West Asian rather than the European tradition. Detailed analysis of the various spectral bands of the spectral image cube along with visual inspection of the large scale colour image showed that the map was not fully planned at the beginning but rather painted in stages, at times by trial and error and that it was unfinished. A new hypothesis for the origin of the Selden map in Aceh Sumatra is proposed based on the new evidences.
\end{abstract}

Keywords: Pigments, Binding medium, Gum Arabic, Animal glue, Spectral imaging, FTIR, Fibre optic reflectance spectroscopy, High performance liquid chromatography, Mass spectrometry, Raman spectroscopy, XRF, SEM/EDX

\section{Background}

The Selden map of China is an early seventeenth century map showing the maritime trade routes in Asia (Fig. 1). At first glance, the map looks like a Chinese landscape painting with very detailed annotations in Chinese of administrative seats in Ming dynasty China and cities and ports in Asia. The map arrived at the Bodleian Library (Oxford) in 1659 and was named after John Selden, a

\footnotetext{
*Correspondence: Haida.Liang@ntu.ac.uk

${ }^{1}$ School of Science \& Technology, Nottingham Trent University, Nottingham NG11 8NS, UK

Full list of author information is available at the end of the article
}

prominent London lawyer who donated the map to the library after his death in 1654. The 'rediscovery' of the map in 2008 by the historian Robert Batchelor with the help of the Bodleian librarian David Helliwell has initiated a burst of research interest in the history and interpretation of the map [1-9]. It is believed that the map shed new light on the global maritime history of the late sixteenth and early seventeenth century. Since 2008, a number of books have been written about the map [2-4] and the Bodleian Library has launched a special exhibition of the map. 


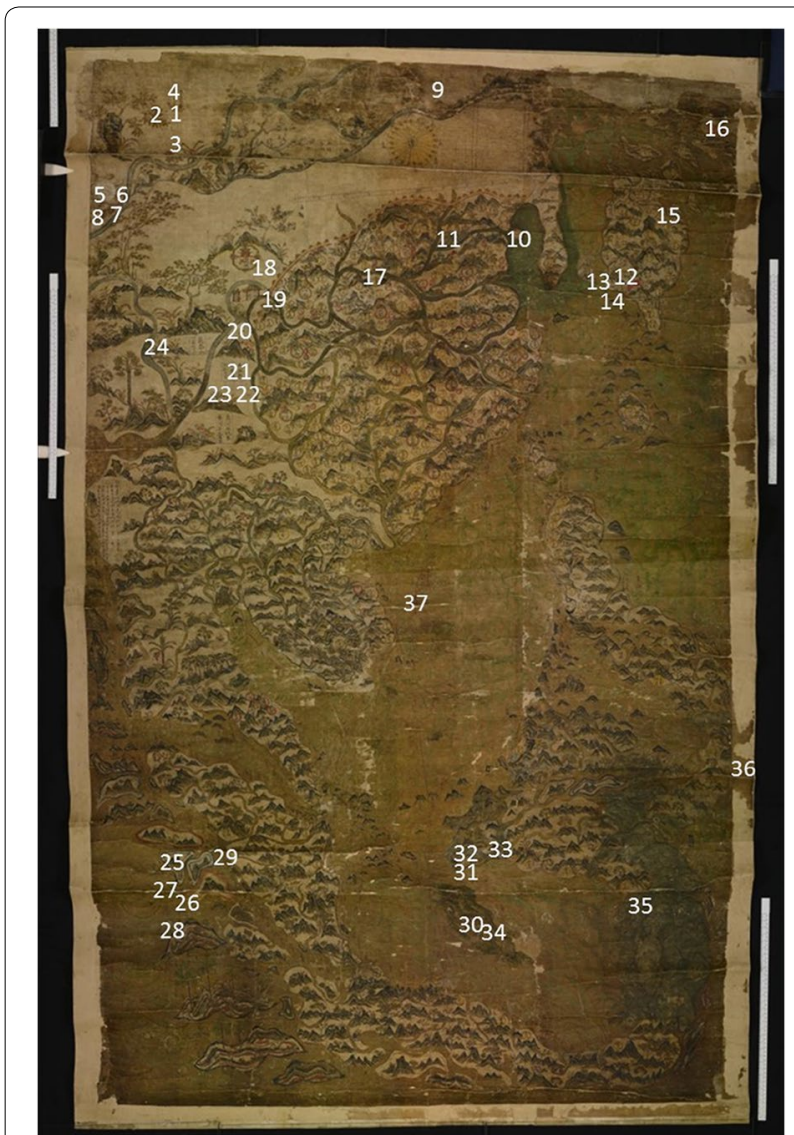

Fig. 1 The Selden map (before the 2011 conservation treatment) with positions marked in white numbers of where spectral imaging data has been collected (the field of view of each image is $\sim 4 \mathrm{~cm}$ ).

The map measures $\sim 96 \mathrm{~cm}$ by $158 \mathrm{~cm}$. The original colour image is $\odot$ The Bodleian Library, University of Oxford, MS Selden Supra 105

Some of the most well-known surviving examples of large scale maps of the Chinese Empire and 'the world' are given by the Map of the Tracks of Yu the Great (禹迹 圖) and the Map of China and Foreign Countries (華夷 圖) carved in stone around 1137 [10]. The former shows a map of China drawn on square grids of equal scales and the latter shows a map of China with text descriptions of foreign places. Chinese maps of the sixteenth and seventeenth century are typified by the Enlarged Terrestrial Atlas (廣與圖) by Luo Hongxian (羅洪先) published in 1555 which were in black ink on rectangular grids [10]. However, the Twenty-eight Mansion, Field-allocation, Imperial Ming, All Provinces Terrestrial World Map (二 十八宿分野皇明各省地輿總圖) from a popular household encyclopedia from Fujian (China) that was reprinted a number of times (e.g. in 1599 and 1607) in black ink without grids is thought to be the source of the China part of the Selden map, except that the Selden map was painted in colour $[1,3]$. Chinese maps were sometimes painted in colour in the tradition of Chinese landscape paintings, for example, the The Amalgamated Map of the Great Ming Empire (大明混一圖) painted on silk is a world map dated to around 1389 that showed the world stretching from China and Japan to Europe, Africa and from Mongolia to Java [11].

Batchelor noticed the importance of the Selden map through the clear depiction of the shipping routes with their compass bearings written next to them ${ }^{1}$, as well as the unique compass rose and ruler as a scale bar at the top of the map. Chinese maps before the twentieth century did not have compass rose and scale bars $[1,3,5]$. The Selden map appears to be a coloured landscape painting style map combined with a nautical chart. The compass rose on the Selden map is a traditional Chinese representation of a mariner's compass with its 24 equal divisions (Fig. 2) rather than the European version with 16 or 32 divisions [10]. The shipping routes have their compass directions marked on them but not the travel times, unlike the famous fifteenth century Chinese nautical chart used by Admiral Zheng He (鄭和航海圖) [12] who sailed from China through South East Asia to East Africa in seven expeditions between 1405 and 1433 . Admiral Zheng He's map was a practical map for sailing with a view from the ship of the landmarks in drawings rather than colourful paintings, and with the compass directions and travel times marked alongside the shipping routes for easy reference. Presumably the scale bar on the Selden map was there to indicate the distance and there was therefore no need to mark the travel times on each route.

Very little was known about the date and origins of the Selden map, as the only information given to the Bodleian Library by its donor in his will was that it was " $a$ map of China made there fairly, and done in colours, together with a sea compass of their making and divisions, taken both by an English commander, who being pressed exceedingly to restore it at a great ransome, would not part with $i t$." The date of the map has been narrowed down since its rediscovery based on extensive research by various historians [1, 3, 6-8]. The range of date for the map proposed by the historians are between 1607 and 1619 based essentially on the activities of the Dutch in South East Asia during this period and place names in Taiwan. The map had marked the occupation of the Spanish (huaren, 化人) in the Philippines (1565 onwards), the division of power between the Spanish and the Dutch (hongmao, 紅 毛) on the Ternate island in Maluku (1607-1662), but did not mention the Dutch control of Jakarta (establishment of Batavia in 1619) or Taiwan (1624-1661). The Dutch

\footnotetext{
1 The trade routes with their compass bearings written in Chinese are best illustrated in the zoomed in images illustrated in Figs. 10, 11 and 15a.
} 


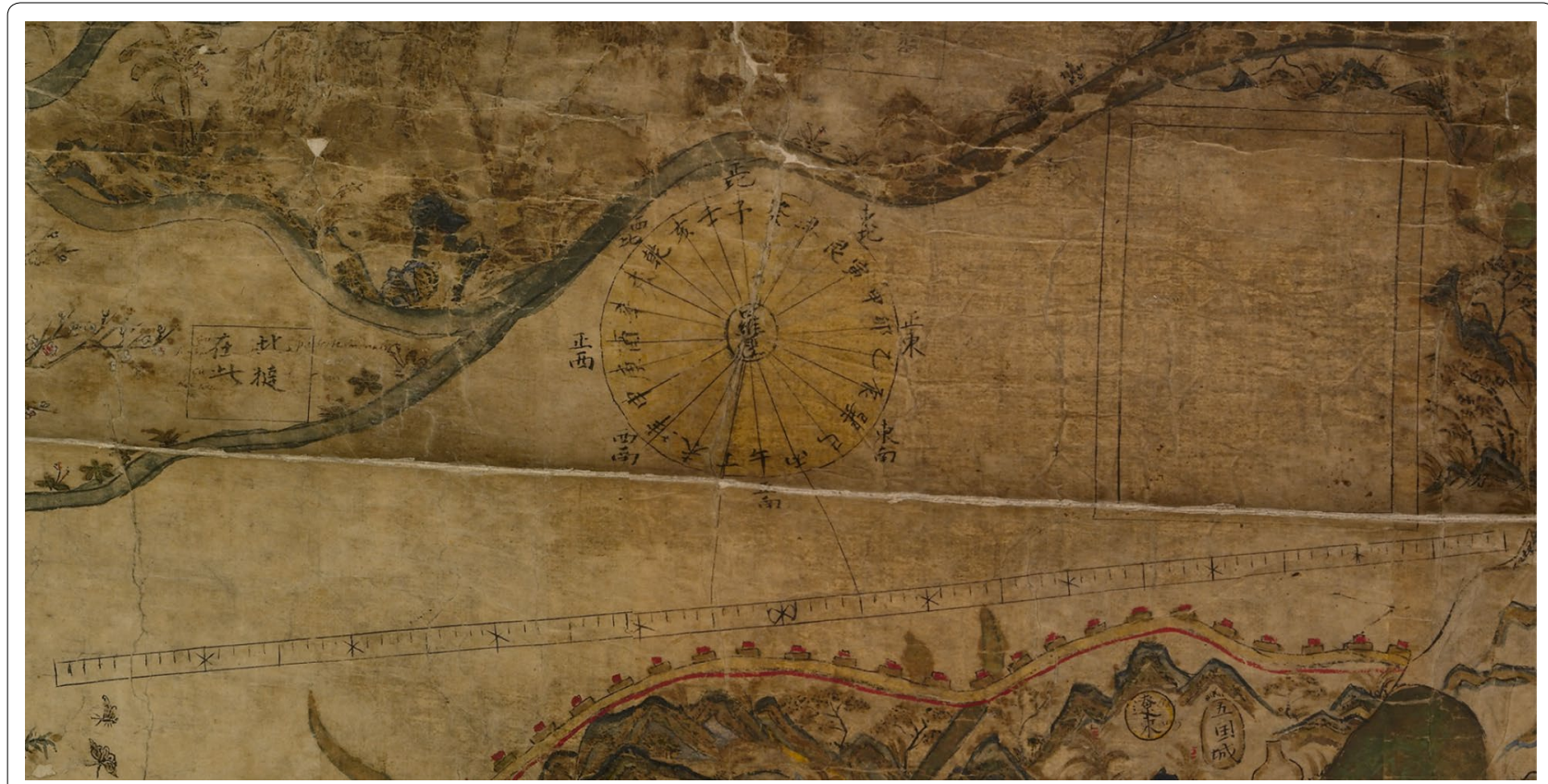

Fig. 2 A detail of the Selden map (before the 2011 conservation treatment) showing the compass rose with its 24 divisions, the ruler (or scale bar) and the empty frame (thought to be a miniature of the map to guide the position of the ruler and the compass directions taking into account of the magnetic declination). ( The Bodleian Library, University of Oxford, MS Selden Supra 105

had conducted a survey of Taiwan and published the first correct map of Taiwan in 1625. The earliest possible date of 1607 is firmly established by the start of the division of power between the Dutch and Spanish on the Ternate island. The latest possible date is less well defined with some arguing that the lack of mention of the Dutch and Spanish in Taiwan indicates that it must be before $\sim 1625$ and the lack of mention of the Dutch presence in Batavia indicates a date before 1619 . This of course depends on how fast the news of an event travels and how important that event was to the cartographer. For example, while the Spanish presence at the San Bernardino strait and at the Ternate island were mentioned, the Spanish presence in Manila since 1571 was not marked on the map.

After the map's arrival at the Bodleian Library, it was studied and annotated in Latin in 1687 by the librarian Thomas Hyde with the help of a Chinese Jesuit convert Michael Shen Fuzong who had arrived at the court of James II from China. It was frequently displayed as an item of curiosity in the eighteenth century but it probably fell into neglect after it was viewed and dismissed as cartographically incorrect by the astronomer and mathematician Edmond Halley [1, 3]. It was remounted in 1919 with a thick paper border and cloth lining which had caused severe cracking of the paper support such that fragments would fall out with each unrolling of the map [13]. The map was finally restored and stabilised in 2011 and it is now once again on display at the Bodleian.
The purpose of this paper is to study the materials and techniques used to paint and draw the map by employing a suite of complementary analytical techniques in order to provide scientific material evidence on the origins of the Selden map as well as the painting and drawing sequence to give insight on how the map was made.

\section{Methods}

Prior to the recent conservation of the map, the Bodleian Library invited the group at Nottingham Trent University (NTU) to perform in situ high resolution spectral imaging of selected regions on the map in June 2009, while in the meantime, detached fragments fallen out during the unrolling of the map were analysed with Fourier Transform infrared spectroscopy in the attenuated total reflection mode (FTIR-ATR) at the Bodleian and sent to the Victoria and Albert Museum (V\&A) to be analysed by micro-Raman spectroscopy and X-ray fluorescence (XRF) spectroscopy. All the detached fragments happened to be from the green areas, which is not surprising given that most of the map was painted in green. It is not possible to know exactly where the detached fragments came from but they have similar reflectance spectra as the green ocean. Some of these samples were then analysed again in 2015 using FTIR-ATR, near infrared (NIR) reflectance spectroscopy, optical coherence tomography (OCT), X-ray diffraction (XRD), scanning electron microscopy and energy dispersive X-ray spectroscopy 
(SEM-EDX) and high performance liquid chromatography (HPLC) hyphenated to a mass resolution mass spectrometry (MS) at NTU. Apart from HPLC-MS and SEM-EDX, all the techniques are non-invasive and can potentially be used on the map directly. This is a deliberate choice as we would hope to apply some of these techniques directly on the map at a future date to confirm some of the results. These techniques have not been applied to the map yet due to the logistics of access and the unavailability in 2009 of some of the instruments or at least ones in a portable form that could be applied directly to the large map. A recent paper published by some of us has shown in detail the complementary use of a suite of non-invasive techniques ranging from spectral imaging to Raman, XRF and OCT that was applied directly to Chinese export water colour paintings of the nineteenth century demonstrating the advantages of a holistic multi-technique approach [14].

\section{Spectral imaging}

The PRISMS spectral imager developed at NTU was originally designed for remote high resolution spectral imaging of wall paintings at distances up to a few tens of metres $[15,16]$. Spectral imaging enables efficient capturing of spectral reflectance at millions of pixels simultaneously [17]. It was modified for close range imaging specifically for capturing the Selden map (Fig. 3a). A Schneider Componon-S 100/5.6 lens instead of the telescope was used and motorised linear stages were used instead of a pan/tilt stage. At the time, PRISMS operated only as a spectral imager in the $400-900 \mathrm{~nm}$ spectral range with 10 bandpass filters spaced $50 \mathrm{~nm}$ apart in central wavelength, each with a bandwidth of $40 \mathrm{~nm}$ except for the $880 \mathrm{~nm}$ filter with a bandwidth of $70 \mathrm{~nm}$. Spectral imaging at a spectral resolution of $40-50 \mathrm{~nm}$ is sufficient for identification of most pigments except for those based on anthraquinone dyes such as madder and scale insect dyes (e.g. lac and cochineal) and cobalt blue pigments such as smalt [14]. The hyperspectral version of PRISMS has sufficient spectral resolution to detect these, but it was not available in 2009.

Calibration was performed with a Spectralon standard (99\% diffuse reflectance) at the beginning and end of each imaging session. The imaging of the Selden map was performed on two consecutive days with a change of the bulb in the light source in the middle of the second day. A mini-Macbeth chart was used to validate the system during each imaging session and some representative results are shown in Fig. 3b, c.

\section{Near infrared (NIR) reflectance spectroscopy}

A fibre optic reflectance spectrometer (LabSpec 4 Benchtop Analyzer) operating in the $350-2500 \mathrm{~nm}$ spectral range with spectral resolution of $3-10 \mathrm{~nm}$ was used on the fragments to help with pigment and binding medium identification using the near infrared spectral range (900-2500 nm). The near infrared spectra can help with distinguishing different binding media and provide additional confirmation for pigment identification.

\section{Mid-infrared (Mid-IR) spectroscopy}

A PerkinElmer Spectrum 100 FTIR-ATR with a diamond crystal was used to examine the fragments for binding medium and pigment identification in the wavenumber range of $400-4000 \mathrm{~cm}^{-1}$ (or $2.5-25 \mu \mathrm{m}$ ). While the technique is non-invasive, it cannot be applied directly on the map. However, a Bruker alpha FTIR with a reflection module can be used as an alternative for direct application on the map in the future.

\section{Micro-Raman spectroscopy}

A Horiba XploRA Raman spectrometer coupled to an Olympus microscope using a $532 \mathrm{~nm}$ and a $638 \mathrm{~nm}$ laser was used to provide highly specific pigment identification on the fragments. Spectra were calibrated when necessary using neon emission lines. The spatial resolution is $2 \mu \mathrm{m}$ when using the $638 \mathrm{~nm}$ laser with a $50 \times$ microscope objective and the maximum laser power used was always less than $0.1 \mathrm{~mW}$ at the sample. While the technique is non-invasive, the size of the map limits the type of Raman instrument that can be used directly on the map. It is in principle possible to perform Raman spectroscopy in situ on the map with a portable Raman spectrometer [18].

\section{Optical coherence tomography (OCT)}

Optical coherence tomography enables non-invasive and non-contact imaging of the stratigraphy of paint and coating layers. The $810 \mathrm{~nm}$ ultra-high resolution OCT (UHR-OCT) developed at NTU has an axial resolution of $1.2 \mu \mathrm{m}$ (in the direction perpendicular to the painting surface) in varnish and paint, and a transverse resolution of $7 \mu \mathrm{m}$ (in the plane of the painting surface) [19]. OCT was used on the fragments to verify if there was any potential coating layers on the map, as it looked very glossy for an East Asian painting [13]. The ultra-high resolution OCT is portable and could be used directly on the map in the future to give a more representative view of the map subsurface microstructure. 


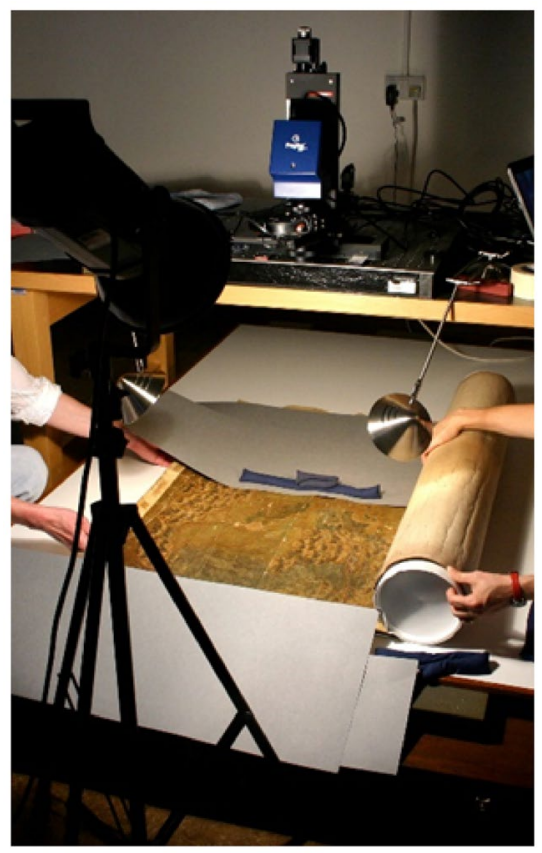

a

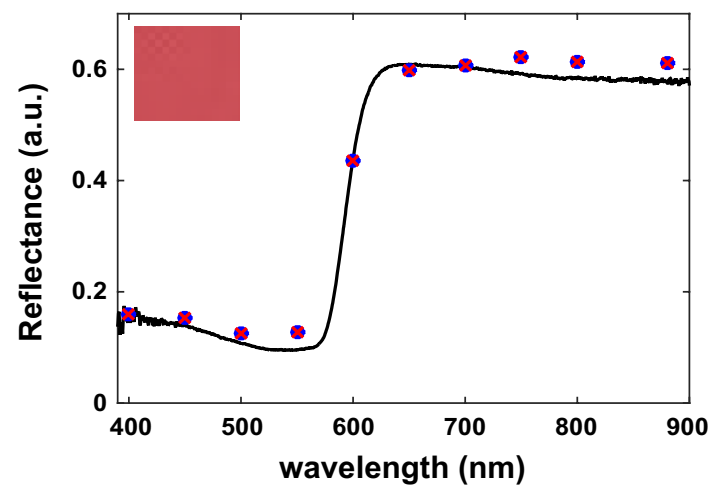

b

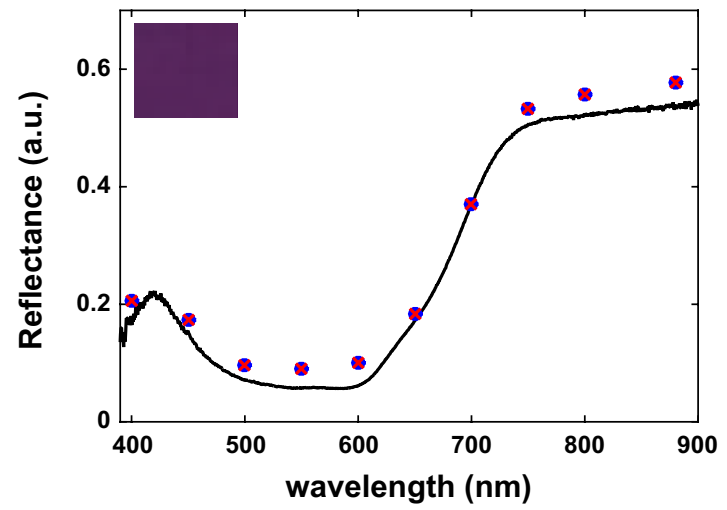

C

Fig. 3 a Spectral imaging of the Selden map using PRISMS at the Bodleian Library; b, c spectral comparison between data collected from colour patches of a mini Macbeth ColorChecker. The black curves are spectra collected by a fibre optic spectrometer and the blue circles and red crosses are calibrated PRISMS data from the first and second day of imaging

\section{X-ray fluorescence (XRF) Spectrometer}

The XRF analysis was performed with the V\&A ArtTAX XRF spectrometer $(50 \mathrm{kV}, 600 \mu \mathrm{A}$, livetime $100 \mathrm{~s})$ on the fragments to identify the elemental content, though it is not sensitive to elements lighter than $\mathrm{Z}<14$ in air. The spatial resolution of the instrument is $200 \mu \mathrm{m}$. The instrument is non-invasive and could potentially be used on the map directly.

\section{Scanning electron microscopy with energy dispersive X-ray (SEM-EDX) Spectroscopy}

Scanning electron microscopy with energy dispersive $\mathrm{X}$-ray can only be used on fragments (not on the map directly), but it is a non-destructive technique which means that other techniques can still be applied to the fragments after the examination. The fragments were examined with SEM-EDX to detect the elements including the lighter elements and thus providing complementary information to XRF for identification of pigments. EDX is a surface technique compared with XRF which is semi-quantitative as the depth of penetration depends on the nature and layer structure of the material.

\section{X-ray diffraction (XRD)}

The PANalytical X'Pert PRO XRD was performed on the fragments for the identification of inorganic pigments in a crystalline form. While it is non-destructive, it can only be applied to the fragments. Transportable forms of XRD can in principle be used directly on the map [20].

\section{High performance liquid chromatography hyphenated to a mass spectrometer (HPLC-MS)}

Mass spectrometry is a destructive technique used here to verify if animal glue was used as a binding medium. One fragment was extracted, alongside appropriate controls, solubilised in $30 \mu \mathrm{L}$ trifluoroethanol and $30 \mu \mathrm{L}$ $50 \mathrm{mM}$ TEAB (triethylammonium bicarbonate) and placed on a heated shaker at $60{ }^{\circ} \mathrm{C}$ for $30 \mathrm{~min}$ [21]. Following this incubation, it was ultrasonicated in a sonicating water bath for $10 \mathrm{~min}$ at room temperature. The 
sonicated sample was centrifuged at maximum speed (Eppendorf benchtop centrifuge) for $3 \mathrm{~min}$ and the supernatant was transferred into a clean microtube. The sample was then dried in a vacuum spin concentrator (Eppendorf Concentrator plus) and re-suspended in $30 \mu \mathrm{L} 50 \mathrm{mM}$ TEAB. The sample was digested with $2 \mu \mathrm{g}$ trypsin at $37{ }^{\circ} \mathrm{C}$ while shaking/agitating overnight, after which the sample was again dried and re-suspended in $20 \mu \mathrm{L}$ LCMS grade $5 \%$ acetonitrile $+0.1 \%$ formic acid.

The sample was then analysed on a SCIEX TripleTOF ${ }^{\circledR}$ 6600 (optimised for proteomic analysis) mass spectrometer hyphenated to an Eksigent nanoLC 425 HPLC system operating in micro flow $(5 \mu \mathrm{L} / \mathrm{min})$. Chromatographic separation was over $60 \mathrm{~min}, 3 \mu \mathrm{L}$ direct injection on a YMC $25 \mathrm{~cm} \times 0.3 \mathrm{~mm}$ Triart-C18 column $(12 \mathrm{~nm}$, $3 \mu \mathrm{m}$ particle size) with a gradient of $2 \%$ mobile phase B (2\% acetonitrile, $5 \%$ DMSO in $0.1 \%$ formic acid) to $40 \%$ over $50 \mathrm{~min}$; to $80 \% \mathrm{~B}$ at $55 \mathrm{~min}$ held for $2 \mathrm{~min}$ then returned to $2 \%$ over $1 \mathrm{~min}$. Mass spectrometric analysis was performed by information dependant acquisition (IDA) using the Duospray ${ }^{\mathrm{TM}}$ source (SCIEX) with a $25 \mu \mathrm{m}$ electrode at $+5500 \mathrm{~V}$ (gas settings GS1 13; GS2 0; CUR 25; TEMP 0). IDA was carried out using parameters of Top 30 (TOFMS 250 ms accumulation time, production $60 \mathrm{~ms}$, total cycle time $2.1 \mathrm{~s}$ ); charge state $2-4$ above a threshold of $200 \mathrm{cps}$; dynamic exclusion for $10 \mathrm{~s}$ using rolling collision energy (optimised for $\mathrm{m} / \mathrm{z}$ of target ion). The tandem mass spectrometry spectra were searched using ProteinPilot 5.0 (SCIEX) with a Swissprot database containing human, bovine, sheep, pig, rabbit, donkey, horse, deer, sturgeon, cod and stock fish species at $1 \%$ False Discovery Rate (FDR) cut off with an identification focus on biological modifications.

\section{Results}

\section{Binding medium}

The most commonly used binding medium for East Asian paintings is animal glue made from animal skin, tendon and bone, all of which contain collagen. Historically, skins of cow, donkey, horse, pig, fish and deer antler were used to produce animal glue in China, but cow hides were by far the most commonly used in China and Japan [22, 23]. In contrast, gum Arabic was the most common binding medium used on paper-based works of art in Europe from the sixteenth century onwards [24] and on illuminated manuscripts from the Safavid and Mughal empires [25, 26]. Occasionally, fruit gums were used as a cheap substitute. Fruit gums were also found on Central Asian wall paintings [23].

The overall map surface looked unusually glossy for an animal glue medium. As explained earlier, only spectral imaging was performed in situ on the map. The spectral coverage was $400-900 \mathrm{~nm}$ which does not give any information on the binding medium. Further investigation was performed only on the detached fragments.

Near infrared fibre optic reflectance spectroscopy (900-2500 nm) can potentially help to identify the binders, but it is important to make sure that spectral features from the pigments or the substrates do not mask the distinguishing spectral features of the binder. The NIR spectral reflectance of a range of common binding media used in European, South, West and East Asian paintings were compared with those of the fragments. Figure 4 shows that oil, egg tempera and beeswax can be excluded, while animal glue, gum Arabic and peach gum have spectral features that are masked by the cellulose features in this spectral range.

Further investigation in the longer wavelength range using FTIR is required to distinguish between gum Arabic, animal glue and peach gum. Figure 5 shows FTIRATR spectrum of a green fragment compared with those of cellulose and the various binding media. The spectrum of the fragment matches closely with that of gum Arabic. The spectrum of the fragment matched better with gum Arabic than peach gum indicating that gum Arabic is a more likely identification (e.g. the absorption lines at 1732 and $1241 \mathrm{~cm}^{-1}$ in the peach gum spectrum are not present or extremely weak in the spectra of the fragment and the reference gum Arabic sample). In addition, the paint side and the back of the fragments were both examined with FTIR-ATR. The spectral match with gum Arabic was only on the paint side, while the back was dominated by the spectrum of cellulose as one would expect (Fig. 6).

The glossy appearance of the overall map surface is more consistent with gum Arabic as a binding medium, since animal glue binder gives a more matt appearance.

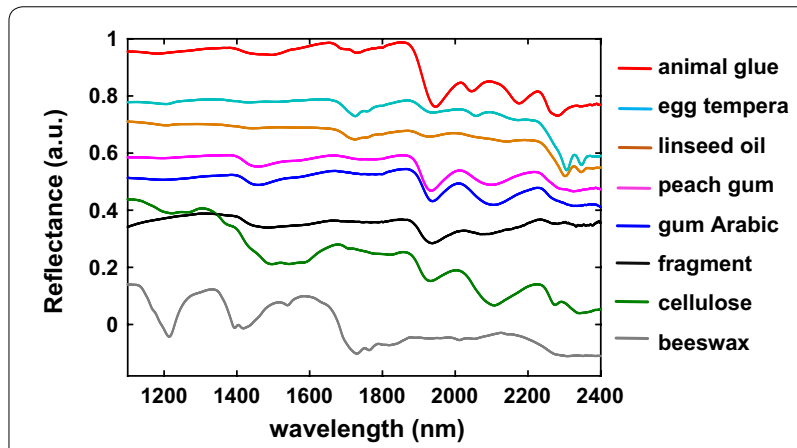

Fig. 4 Near infrared spectra of binding media applied on microscope slides: animal glue (red curve), egg tempera (light blue curve), linseed oil (orange curve), peach glue (magenta curve), gum Arabic (blue curve), beeswax (brown curve) compared with the corresponding spectrum of a green fragment from the Selden map (black curve) and the spectrum of cellulose (Whatman CC41, green curve). The spectra are vertically shifted apart for clarity 


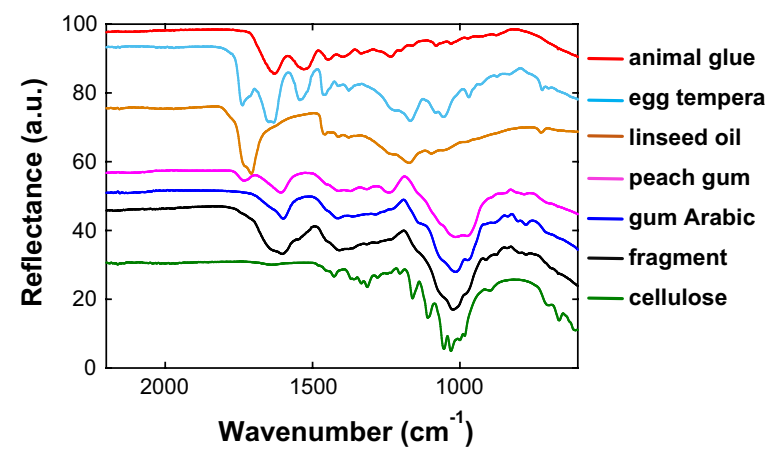

Fig. 5 FTIR-ATR spectra of binding media (small samples taken from those used in Fig. 4): animal glue (red curve), egg tempera (light blue curve), linseed oil (orange curve), peach glue (magenta curve), gum Arabic (blue curve) compared with the corresponding spectrum of a green fragment from the Selden map (black curve) and the spectrum of cellulose (Whatman CC41, green curve). The spectra are vertically shifted apart for clarity

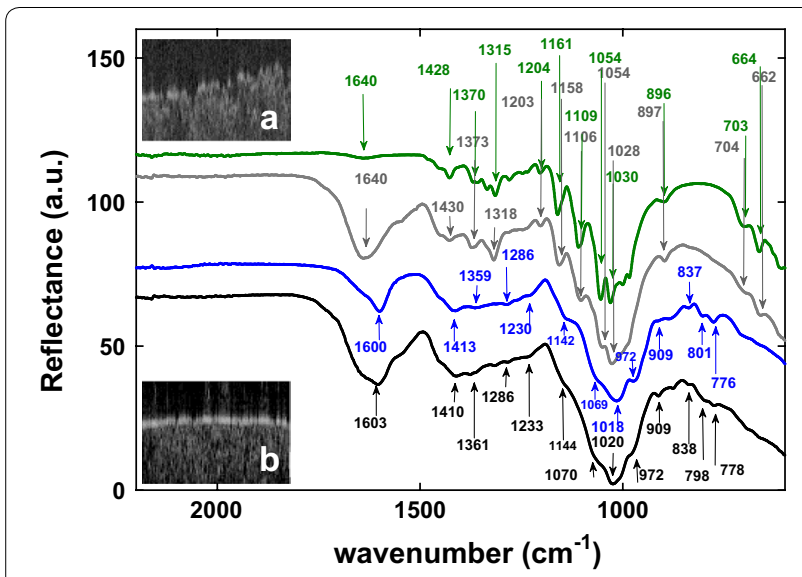

Fig. 6 FTIR-ATR spectra of a green fragment measured from both the paint (black curve) and paper (grey curve) sides compared with the spectra of gum Arabic (blue curve) and cellulose (Whatman CC41, green curve). The spectra are shifted vertically for clarity. Inset: UHR-OCT virtual cross-section images of $\mathbf{a}$ the paper side and $\mathbf{b}$ the paint side of the fragment (the bright line at the top is the interface between air and the painting surface). OCT image dimensions are $0.82 \mathrm{~mm}$ (width) by $0.05 \mathrm{~mm}$ (depth)

However, this result is surprising as the traditional Chinese (and East Asian) painting medium is animal glue. There is a possibility that the map was painted with an animal glue binder but later consolidated with gum Arabic, a method for the consolidation of watercolours in Europe. The map was conserved at least once in the early twentieth century and possibly once or twice prior to that $[1,13]$. Given that the paint was flaking and optical microscopy examination of the fragments found them to be medium rich, it seemed prudent to consider the possibility that the map was consolidated with gum Arabic.

The fragment was first examined with our UHR-OCT to obtain non-contact virtual cross-section images both on the paint side and the back (Fig. 6 insets a, b). If a significant amount of gum Arabic was applied as a consolidation agent, it might be possible to see a layer of it above the paint layer, however, as is shown in Fig. 6b, no coating layer is seen at a resolution of $1.2 \mu \mathrm{m}$.

To further confirm that animal glue was not the binding medium, one of the fragments was tryptically digested and analysed with mass spectrometry. To test the sensitivity of this technique using the setup available, a preliminary study was performed on a similar size fragment cut out from an artificial sample of indigo in as little amount of animal glue as possible, painted on Chinese paper and covered in a thick layer $(80 \mu \mathrm{m})$ of gum Arabic. The artificial sample is meant to represent the worst case scenario where the animal glue content is low and the gum Arabic content is high. Despite the expected reduction in the digestive ability of trypsin as a result of the addition of this gum Arabic, the examination of the artificial sample showed that the platform was capable of detecting peptides derived from three separate types of bovine collagen (1330 total bovine peptides identified at $1 \%$ false discovery rate from the three collagen types). In contrast, examination of the map fragment did not detect collagen proteins that were distinguishable from those identified within the controls. The absence of collagen would strongly suggest that animal glue is not the binding medium. However, trace amount of proteins were identified from bovine and sheep casein which are usually associated with a glair binder (milk) sometimes used in European manuscripts but not in East Asian paintings. Sheep milk is sometimes used with a gum Arabic binder to improve the texture of a paint such that of vermilion in the Indo-Persian tradition [40]. Alternatively, the trace amount of casein may simply be a contaminant.

In conclusion, the binding medium for the map is most likely gum Arabic which is a common binding medium for illuminated manuscripts in Europe [24], the Safavid and Mughal empires [25, 26] but not used in Ming China. While it would be useful to verify this result over various parts of the map, the overall glossy appearance of the map suggests that the fragment is likely to be representative of the map.

\section{Pigments and dyes}

The Selden map is in the style of traditional Chinese landscape paintings which is composed of mountains, plants, rivers, the sea and the occasional houses and pavilions. In this case, the plants are not just decorations but are sometimes geographically accurate depiction of 
the local plants; many of which are also the commodities that attracted the maritime trade [1]. The following colours were found on the map: red, blue, green, yellow, brown, white and black. The paper substrate is of a light brown colour while much of the background on land are in a darker brown colour. The leaves are in a brownish green colour. Some of the flowers and plants, parts of the Sun and some parts of the architectural structure were painted in red, red circles were painted around the constellation signs (or lunar mansions) and some place names outside China, while red decorations were painted around the names of the provinces and the two capitals of Ming dynasty (1368-1644) China and a dull red colour delineates some of the islands. Mountains were often highlighted in blue while the Yellow River was also painted in blue. The sea, some of the mountains, boundaries between provinces in China and between countries outside China were painted in green. Names of cities and ports except for the two capitals of China were circled in bright yellow. While province names in China are circled in brown with red decorations, names of places in Manchuria and the name of the kingdom of Korea were circled just in brown. The Sun, the Moon and the clouds around them were painted in white. All the writings and drawings are in black.

As demonstrated in previous studies [14, 17], spectral reflectance in the visible and near infrared can be used for the identification of single pigments or multiple pigments using a Kubelka-Munk (KM) [27] fit with a comprehensive spectral library of historic artists' paints. KM models calculate the resulting spectral reflectance from a mixture of single pigment paints using a reference paint spectral library. The concentration of each pigment component is set as a free parameter such that the KM model using the reference spectral library gives a best fit to the unknown spectrum with an indicator for goodness of fit for each combination of pigments. It can also be used simply to test if a certain combination of pigments can produce a good fit to the unknown spectrum [14]. The reference spectral library used was one that was suited to the identification of historic Chinese artists' paints with animal glue as a binding medium and Chinese Xuan paper as a substrate [14]. Different binders can change the ratios between the intensity of the absorption lines but not the positions [17]. Therefore exact match is not expected between the reference spectra and those collected from the map.

The colorant used in the blue areas are all identified with the characteristic spectrum of indigo using the reflectance spectra extracted from the PRISMS spectral image cube. Figure 7 gives an example of the identification of indigo used in the dark blue ring surrounding the red island next to the writing that appears to indicate the
Spratly islands. Not only is the reflectance spectrum consistent with indigo (Fig. 7c), the transparency of the dark blue colorant in the near infrared is also consistent with indigo (Fig. 7b).

A bright yellow colour is used in the map to indicate cities and ports. It is difficult to distinguish between the yellow pigments gamboge, orpiment and massicot (yellow pigments known to be used on East Asian paintings [23]) using the spectral reflectance data in the 400$900 \mathrm{~nm}$ range [14]. The yellow paint is highly transparent as the black ink remains clearly visible through the yellow paint. It is therefore likely to be an organic yellow such as gamboge, since orpiment and massicot are both highly scattering and relatively opaque. A portable XRF will easily distinguish between the three possibilities and a portable Raman can potentially identify these pigments with certainty as long as the laser-induced fluorescence does not mask the Raman signal.

Large areas of the map were painted with green since the sea dominated the map. Most of it was in a brownish green colour but some areas were with brighter green highlights. In traditional Chinese paintings on paper or silk, greens were usually painted with malachite or an organic green composed of indigo and gamboge or layers of the organic green painted above layers of malachite $[22,23,28]$. The reflectance spectra extracted from PRISMS image cubes in both the bright green and the brownish green regions were consistent with a malachite (or atacamite as the spectra of the two types of copper greens are indistinguishable in the visible), indigo and orpiment (or gamboge) mix (Fig. 8a, b). The spectrum is not consistent with either a single malachite or atacamite pigment or a simple mixture of indigo and orpiment (or gamboge). To confirm the pigment identification, other analytical techniques are necessary, but unfortunately no other techniques were applied directly on the map. However, a number of green fragments found to be detached from the map were analysed further. The green fragments were found when the map was unrolled, and their exact location on the map is not known. However, the reflectance spectra of the green fragments are consistent with those brownish green areas in the ocean (Fig. 8a, b) suggesting that they were most likely to be from the green ocean regions.

Three green fragments were examined by the XRF. Copper was found to be the main element while $\mathrm{Ca}$ and $\mathrm{Fe}$ were also found with trace amounts of $\mathrm{K}$ for all three fragments. In addition, two of the fragments had trace amounts of arsenic (As). The identification of $\mathrm{Cu}$ is consistent with malachite but there are other copper greens such as basic copper chlorides, $\mathrm{Cu}_{2} \mathrm{Cl}(\mathrm{OH})_{3}$, that is atacamite and its three isomers, and the synthetic copper acetate pigment verdigris. It is difficult to distinguish 


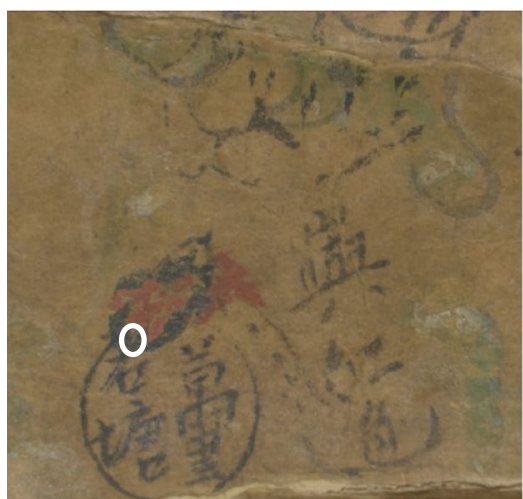

a

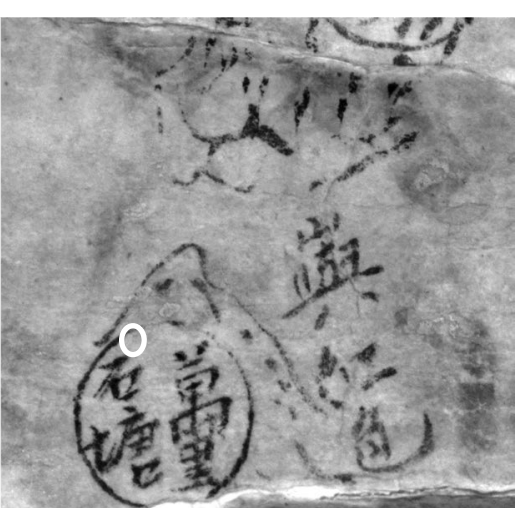

b

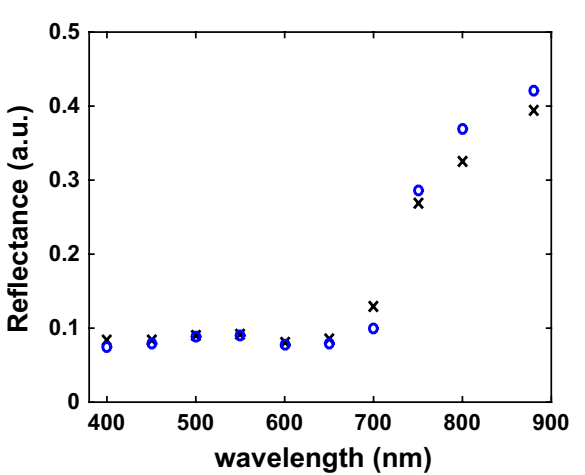

C

Fig. 7 Identification of the blue colorant: a colour image of'Area 37' on the Selden map (Fig. 1) derived from PRISMS data using CIE (Commission Internationale de I'Eclairage) standard D65 illumination and the 2 degree standard observer; the white circle marks the position where the reflectance spectrum was extracted and $\mathbf{b}$ near infrared $880 \mathrm{~nm}$ PRISMS image; $\mathbf{c}$ the reflectance spectrum extracted from the dark blue area (black crosses in the spectrum) is fitted by the KM model using a reference spectrum of indigo (blue circles)

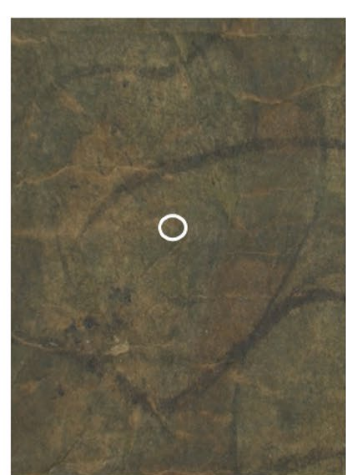

a

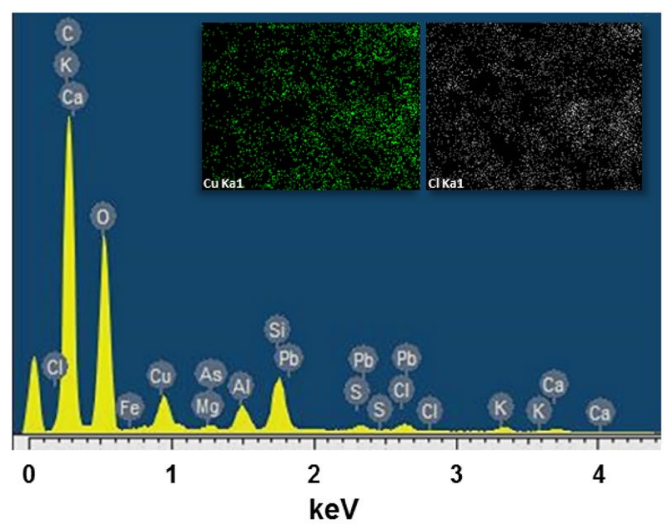

C

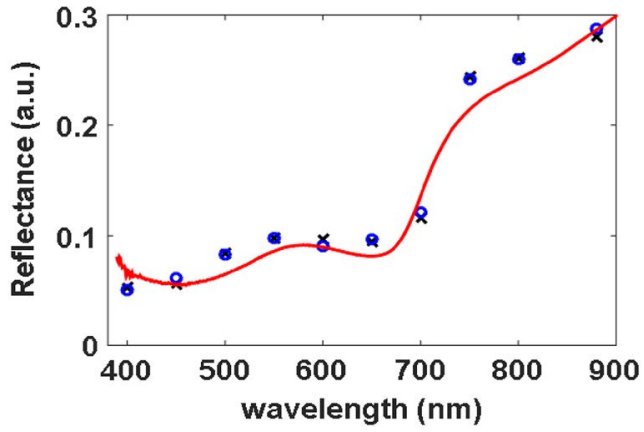

b

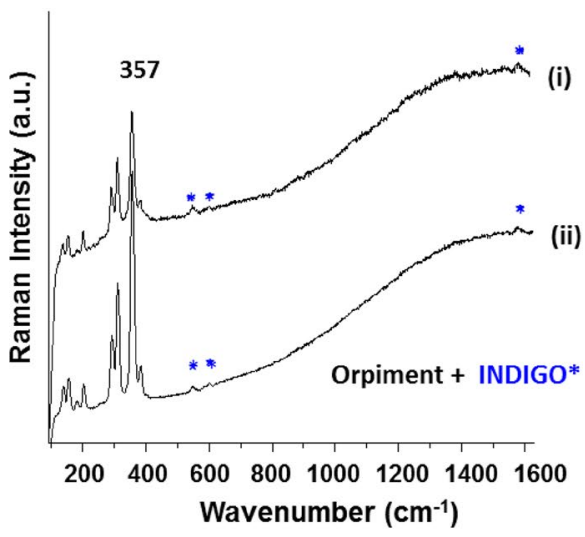

d

Fig. 8 a Colour image derived from PRISMS images of 'Area 35' on the Selden map (Fig. 1) with a white circle marking the position where the reflectance spectrum was extracted; $\mathbf{b}$ KM model fit (blue circles) using a combination of atacamite, indigo and orpiment to the measured PRISMS reflectance spectrum (black crosses) for a green area; the spectrum of a green fragment measured with a spectrometer (red curve) is also plotted to show the spectral similarity between the fragment and the green region on the map; c EDX spectra from a green fragment showing the presence of copper, chlorine and arsenic; the left inset shows the SEM copper map and the right inset shows the SEM chlorine map; $\mathbf{d}$ Micro-Raman spectra from two green fragments showing spectral features corresponding to orpiment and indigo 
between these pigments using reflectance spectroscopy in the 400-900 nm range. Basic copper chlorides have also been found on wall paintings and architectural paints in China, while verdigris has never been found on any Chinese paintings $[23,29,30]$. The fragments were then analysed by Raman microscopy. Under the optical microscope, the green fragments looked very medium-rich with fine green particles, some blue particles and the occasional red, black, transparent white/ yellow/orange particles. The medium was probably responsible for the high fluorescence under Raman. The green particles were analysed but did not yield any Raman signal except for one particle on the surface which was identified as malachite. Copper greens are in general poor Raman scatterers. The particle identified as malachite was loose and sitting on the surface and not fully enveloped in the binding medium. Either malachite was part of the cartographer's palette, or it was a contaminant. The fragments were also examined with $\mathrm{XRD}$ but the $\mathrm{Cu}$ green pigment did not yield any signal which might be because it is amorphous. SEM-EDX measurements were made on the fragments both at the front painted side and at the back. Copper and chlorine were detected at the ratio of 2:1 and the co-location of $\mathrm{Cu}$ and $\mathrm{Cl}$ were found in the SEM-EDX maps (Fig. 8c insets) suggesting that the copper green pigment might be a basic copper chloride such as atacamite [31]. Raman spectroscopy identified the blue particles as indigo confirming the identification from spectral imaging, while the occasional yellow crystals were identified with orpiment (Fig. 8d). Both fibre optic NIR reflectance spectroscopy and FTIR-ATR were used to analyse the fragments in order to extend the wavelength range from $400-900 \mathrm{~nm}$ to $17 \mu \mathrm{m}$ (or $600 \mathrm{~cm}^{-1}$ ) in the mid-infrared (Figs. 4, 5, 6) to find additional spectral feature that could be attributed to any of the known $\mathrm{Cu}$ green pigments (absorption lines in the range 2140-2500 $\mathrm{nm}$ and $\left.1700-600 \mathrm{~cm}^{-1}\right)$ or the potential yellow pigments gamboge (absorption line at $1191 \mathrm{~nm}$ and $1700-600 \mathrm{~cm}^{-1}$ ) and orpiment (absorption lines in the range 1700$600 \mathrm{~cm}^{-1}$ ). However, the fragment did not contain any spectral features that allowed identification of these pigments. In fact the fragment's spectrum in the FTIR range is nearly identical to that of the gum Arabic reference. The non-detection of any additional spectral features corresponding to the copper greens or the yellow pigments in the FTIR-ATR data may be due to the low concentration. The trace amount of arsenic detected by $\mathrm{XRF}$ and the identification of orpiment by Raman of the occasional yellow crystals suggest that orpiment was mixed with indigo, and possible a basic copper chloride (e.g. atacamite) and/or malachite to produce the brownish green colour.
To verify the above conclusions on the composition of the green area, more measurements directly on the map with XRF, portable Raman, near and mid infrared reflectance spectroscopy will be necessary.

There are essentially three tones of red used on the map, orange red used for flowers, deep red used for flowers or as architectural decorations or to circle the constellation signs and dull red used on islands. Figure 9 shows that the spectrum of a deep red is consistent with vermilion, while the reflectance spectra of dull red regions are consistent with a mixture of vermilion and indigo. The spectrum of the orange red in Fig. 9c is not consistent with the spectrum of just vermilion or just red lead (spectra not shown). XRF combined with high resolution reflectance spectroscopy and Raman will help to identify the pigment or pigment mixture. In traditional paintings from China, organic reds such as anthraquinone dyes were often used for painting flowers [22, 23]. To detect anthraquinone dyes, it is necessary to use higher spectral resolution instruments such as the hyperspectral version of PRISMS or the fibre optic reflectance spectrometer in the visible spectrum.

In summary, the blue areas were painted with indigo, while the green areas were painted with indigo, a copper green (likely to be a basic copper chloride and possibly malachite) and a trace amount of orpiment. The yellow regions were most likely painted with an organic yellow such as gamboge. The red areas were painted with vermilion and the dull red areas were painted with vermilion and a small amount of indigo. The suite of non-invasive techniques applied on the green fragments need to be applied directly on the map to areas of other colours to confirm the identification of the yellow pigments and give a fuller picture of the colorants used and the way they were used.

\section{Techniques and signs of alteration}

It has been noted by previous studies that the tilt of due north on the compass rose (marked by the character ' 子') from the vertical axis of the map indicates the magnetic declination (Fig. 2) [5]. The map north is given by the vertical sides of the empty box (thought to be a miniature version of the map frame [5]) and the magnetic north is given by due north on the compass rose. Given the deliberate tilt of the ruler and due north of the compass rose, it seemed that the cartographer would have taken care to draw this tilt of $\sim 6^{\circ}-8^{\circ}$ west relative to the vertical edges of the empty box, i.e. direction of map north. The International Geomagnetic Reference Field (IGRF) model for historic magnetic declination from 1590 onwards based on historic maritime navigation records from early European explorers [32] give a value of $\sim 0.35^{\circ}-0.71^{\circ}$ east for Quanzhou (泉州), $3.7^{\circ}-4.0^{\circ}$ east for Nagasaki, 


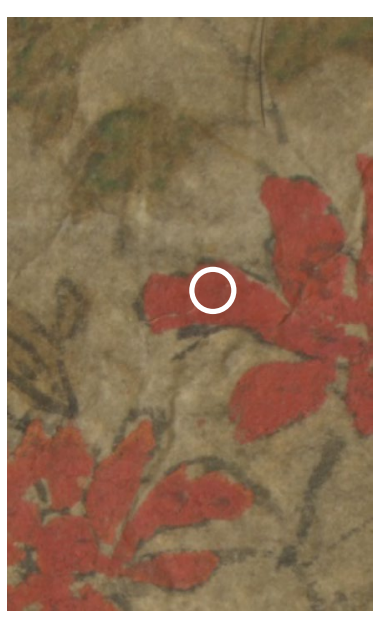

a

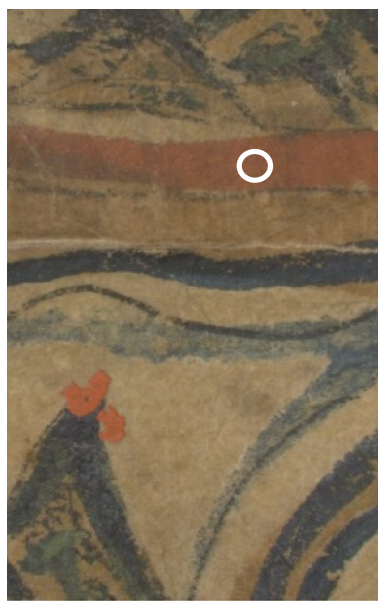

C
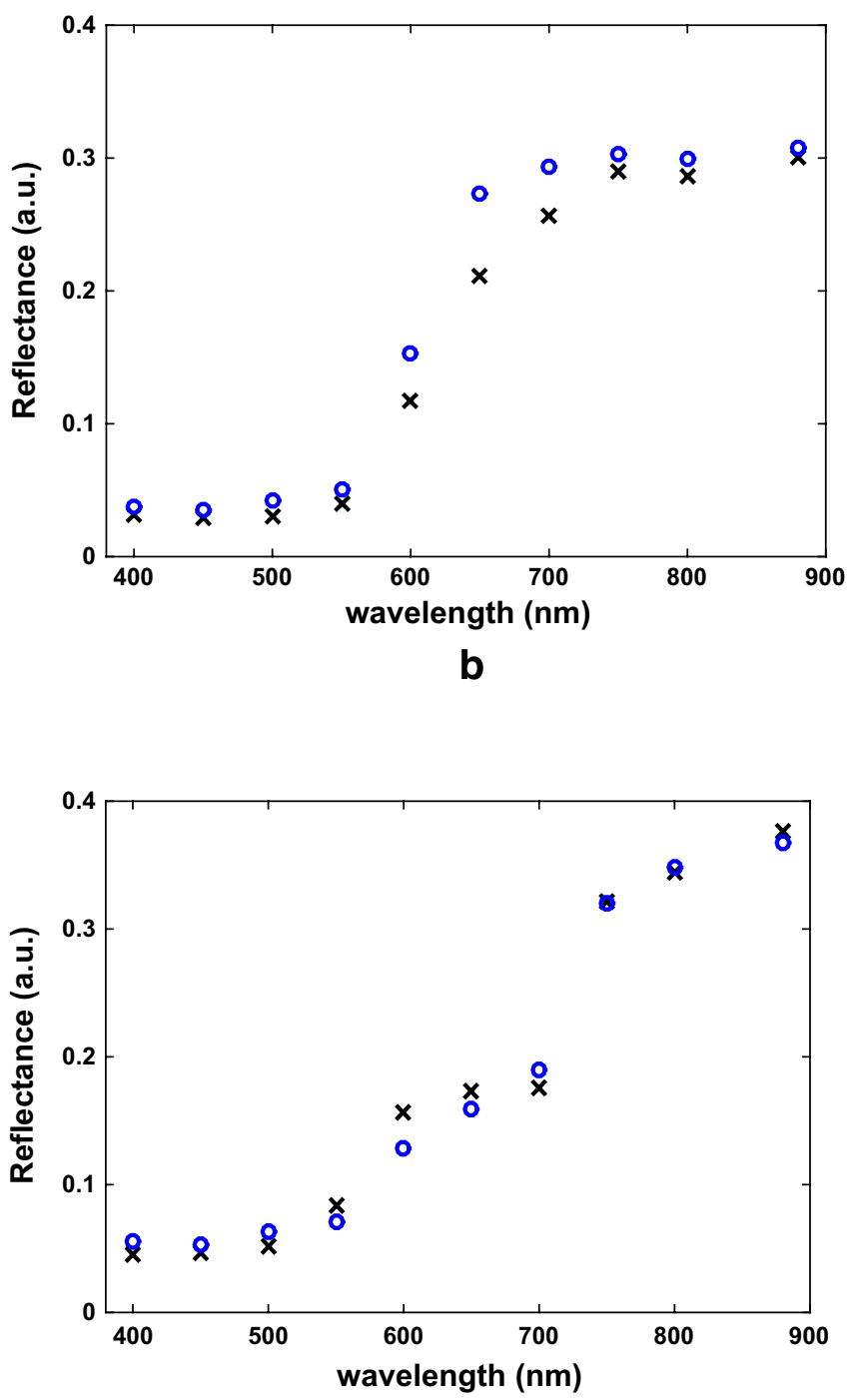

d

Fig. 9 a A detail of the colour image derived from the spectral image cube of 'Area 12' on the Selden map in Fig. 1 (the white circle indicates the position where the spectrum was extracted); $\mathbf{b}$ the reflectance spectrum extracted for the red area (black crosses) fitted with the KM model using a reference spectrum of vermilion (blue circles); c Colour image derived from the PRISMS image cube of 'Area 25' on the Selden map (the white circle indicates the position where the spectrum is extracted) and $\mathbf{d}$ the reflectance spectrum extracted from a dull red area (black crosses) fitted with the KM model using as reference pigments vermilion and indigo (blue circles)

$\sim 1.8^{\circ}-2.2^{\circ}$ east for Manila, $\sim 3.4^{\circ}-2.8^{\circ}$ west for Jakarta, $\sim 5.7^{\circ}-5.0^{\circ}$ west for Aceh and $15.4^{\circ}-14.3^{\circ}$ west for Calicut between 1607 and 1625 . The port on the Selden map that has a magnetic declination during this period closest to the tilt of $\sim 6^{\circ}-8^{\circ}$ west is Aceh. If we believe that the magnetic declination drawn on the map corresponds to where the map was made, then this points to Aceh.
On the other hand, given that the map axis roughly runs through Beijing, it is possible that the value of the magnetic declination corresponded to that of Beijing. If this tilt was indeed of the order of $2^{\circ}$ west for Beijing as suggested by the IGRF model, it would seem hardly worth the trouble to draw the tilt as it would have been barely noticeable on the map. One could argue that the 
geomagnetic model was built on historic navigational data and therefore not necessarily so accurate for Beijing. However, it just so happened that an accurate measurement of the magnetic declination of Beijing ${ }^{2}$ was made by the Ming prince, mathematician and musicologist Zhu Zaiyu (朱载堉) [33] sometime between 1567 and 1581 and he found it to be $1 \frac{1}{3} / 100$ th of a full circle, i.e. $4.8^{\circ}$ west $[33,34]$ with an accuracy of $1.2^{\circ}$. An extrapolation of the geomagnetic model above from 1590 backwards $\left(3.1^{\circ}\right.$ west for Beijing, moving at a rate of $0.06^{\circ}$ west per year) to 1567 and 1581, when Zhu made the measurements, gives $4.5^{\circ}$ to $3.6^{\circ}$ west which is remarkably consistent with Zhu's measurement of $4.8^{\circ} \pm 1.2^{\circ}$ west indicating that the IGRF model is applicable to central parts of China away from the sea. The tilt drawn on the map is $\sim 6^{\circ}-8^{\circ}$ west which is just marginally consistent with this value. If we assume that the cartographer had accurate knowledge of the contemporary magnetic declination of Beijing, then this would suggest that the map was made much earlier (in sixteenth century) than the current favoured range of 1607-1619 which is not possible given an historical event happened in 1607 was recorded on the map. The other possibility is that the cartographer's knowledge of the magnetic declination was out of date and he simply used the latest record available to him. For example, the cartographer may have borrowed from writings by $\mathrm{Xu}$ Zhimo (徐之镆 or Hsu Chih-Mo in Needham) around 1580 that suggested the magnetic declination at Beijing was around $7.5^{\circ}$ west [35] which is most likely not a precise measurement but rounded off to the nearest subdivision, i.e. half a division on the compass. ${ }^{3}$ It seems more likely that the magnetic declination presented on the map was a rough one copied from earlier books, since the China part of the map was copied from an earlier map from the Fujianese encyclopedia [3] which contained all the place names of cities in the 1578 imperial Ming census but did not include a number of places that gained city status between 1595 and 1609 [6].

While the cartographer has taken care to represent the tilt of the magnetic north, he did not seem to have taken care on drawing the 24 divisions on the compass rose

\footnotetext{
${ }^{2}$ It is not recorded in Zhu Zaiyu's writings [33, 34] where he took the measurements of magnetic declination. Scholars argue that it was either measured in Beijing or Luoyang close to his residence. Traditionally such data were recorded for the capital, however, Ming law decrees that Zhu being a prince is not allowed to leave his principality and enter the capital (Beijing in this case) without special permission from the court, thus making it more likely that he took the measurements near his residence (Dai Nianzu private communications). However, the two cities are close enough that the difference in magnetic declination is much less than the accuracy of his measurements and therefore this uncertainty is inconsequential in our case.

3 The Chinese mariner's compass is divided into 24 divisions (i.e. $15^{\circ}$ per division), but compass needle directions are often quoted to the nearest half division that is $7.5^{\circ}$.
}

accurately. The divisions were not evenly spaced resulting in directional errors as large as $7^{\circ}$ (Fig. 2). The divisions between $30^{\circ}$ and $60^{\circ}$ clockwise from the magnetic north and those in the exact opposite directions were drawn $7^{\circ}$ clockwise from the correction direction. The other directions were correct to $4^{\circ}$. Given the accuracy with which the compass rose was drawn and that the smallest division the compass bearings marked on the trade routes indicate a half division (of the 24 major divisions marked on the compass), it seems reasonable to take $7.5^{\circ}$ as the error margin for the actual directions drawn and consider only those that are off the compass bearing by an amount greater than $7.5^{\circ}$ as an anomaly. It has been argued that the errors in the trade route direction compared with the compass bearing directions marked along the routes (see Chinese characters marked next to the black line in Fig. 10) indicated lack of knowledge of a particular part of the world or problems in cartography such as methods to project a spherical earth onto a planar map. However, the error margins assumed in those analysis were much smaller than the cartographer took care to achieve. In addition, the inconsistencies are only between directions drawn and the directions written along the routes, which can only give us clues as to how the cartographer drew the map rather than his knowledge about the region.

During the recent conservation of the map, the main trade routes were found to be drawn at the back of the map [13] (see Fig. 4 in [1]). It was suggested that the trunk routes may have been drawn first before the rest of the map. A detailed examination of the map shows that the trade routes (Fig. 10) and in general the fine ink drawings (Fig. 10) were executed before the colorants were applied. Figure 10a shows that the trade route is intersected by a white and a dark paint at the top and by dark paints further down. The pattern painted in white has clearly been painted-in uninterrupted by the trade route as shown in the $400 \mathrm{~nm}$ (near UV) image (Fig. 10b) which shows just the top white layer on the surface, while the $880 \mathrm{~nm}$ (near infrared) image (Fig. 10c) shows a faint trace of the trade route under the thinner regions of the white paint (the trade route is better shown as uninterrupted in Fig. 10d). The dark drawings across the trade route disappears in the $800 \mathrm{~nm}$ because they were painted with indigo which is transparent at $880 \mathrm{~nm}$. By comparing the images in Fig. 10, one can deduce that the trade routes were drawn first followed by indigo drawings and then a top layer of white paint. However, this does not answer the question of whether the coastlines or the trade routes were drawn first.

The trade routes from Quanzhou (泉州) eastwards to Goto island (五島) just off the coast from Nagasaki and the route westwards along the south China coast to Pahang (彭坊) via Champa (占城) at the south tip 


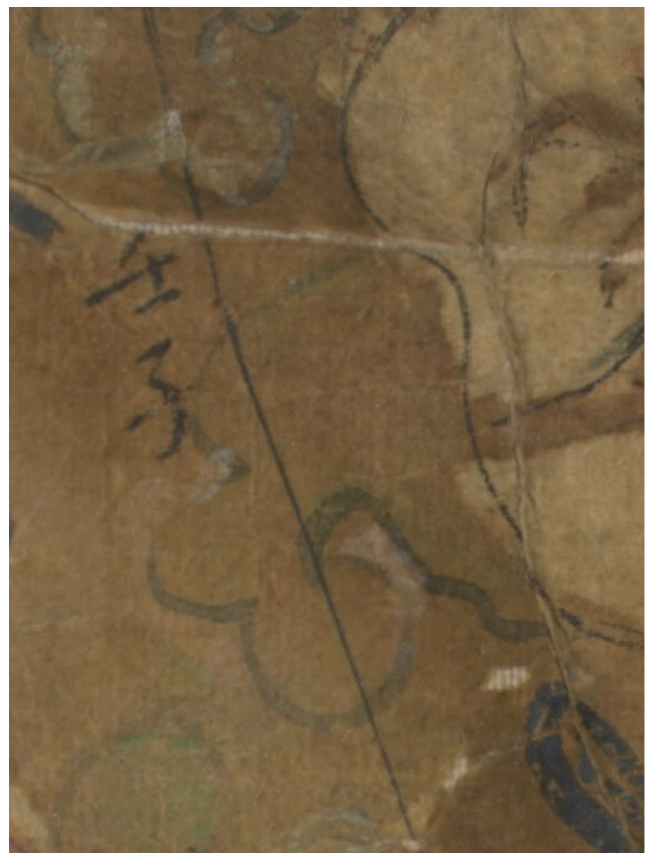

a

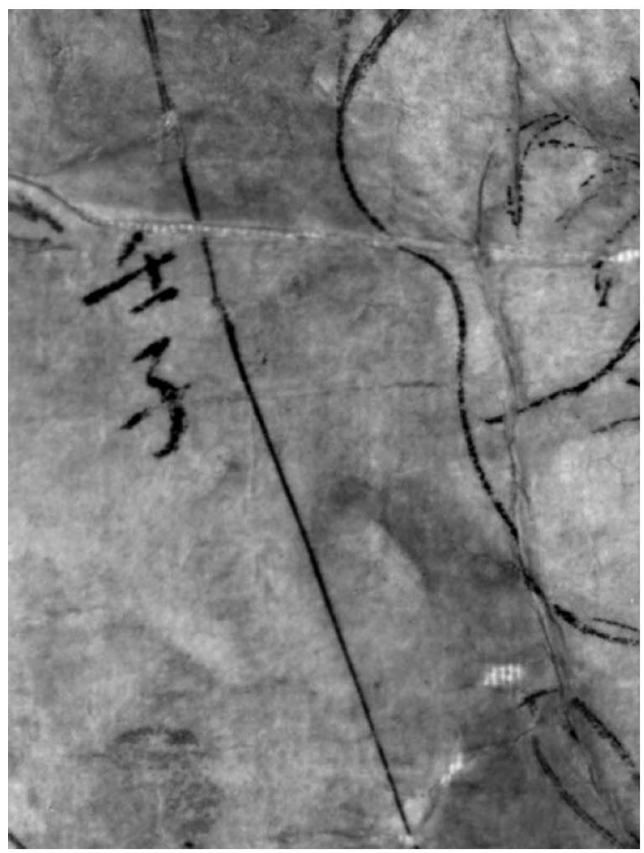

C

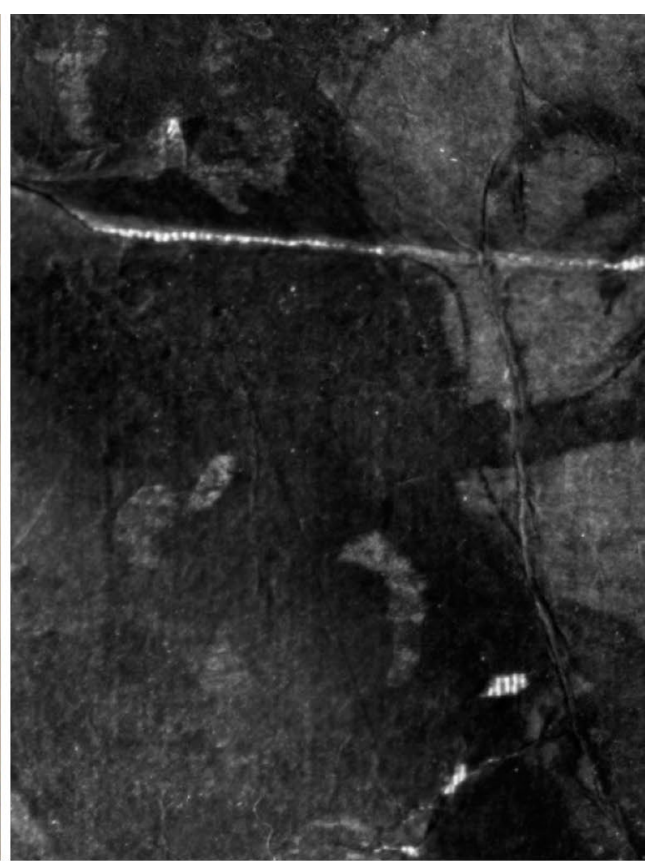

b

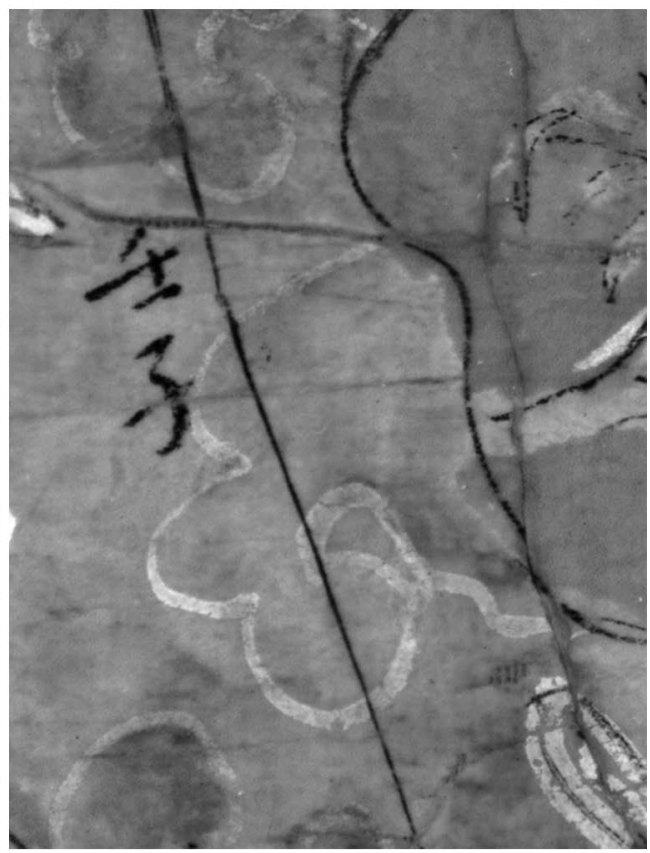

d

Fig. 10 Trade routes drawn in 'Area 29' of the Selden map in Fig. 1 showing that they were drawn before the colorants were applied: a colour image, b $400 \mathrm{~nm}$ near UV image and $\mathbf{c} 880 \mathrm{~nm}$ near infrared image showing the black carbon based drawings and the copper green paint show up in dark grey; $\mathbf{d} 600 \mathrm{~nm}$ image subtracted from $880 \mathrm{~nm}$ image showing both the carbon black drawings (the cracks in the map show up as dark grey) and the indigo drawings (shows up as white though some parts of the brown to the right also show up as light grey). Note that the trade routes are usually accompanied by Chinese characters that indicate their compass bearing 
of Vietnam were found on the back of the map [1, 2, 13]. These routes together runs across the diagonal of the map and looked similar to the routes on the front of the map, suggesting that they were drawn first as an anchor that the rest of the map relied on (see Fig. 25 in [2]). These trunk routes were some of the busiest in this period. Figure 11 shows further evidence that other routes were also drawn first before the coastlines and the landmass. Figure 11a shows the southern Vietnam and Cambodia coast including the southern part of the trunk route described above (route marked 'T' in Fig. 11a) and the various attempts at a number of routes in that area. This shows that the cartographer was at least drawing this part of the map by trial and error. The trade routes were drawn first but only to be replaced by land when he realised that he did not leave enough space for the land. They were re-drawn further down in parallel to the original ones but found to be inadequate again and had to be drawn yet again. These routes were drawn accurately according to their compass bearings, presumably because they were drawn first and were not constrained by the coast. Similarly, Fig. 11b shows that a small segment of the trade route within the coastline next to Bali was not only drawn first but the compass bearing was also marked next to it. This was only to be incorporated into the coastline with another line drawn in parallel to it off the coast above. This stretch of the route was significantly off the compass bearing except for this small section that was drawn before the landmass. The island of Java is at the bottom of the map and presumably the cartographer realised that he might not have enough room to draw it with the initial position of the trade route.

An analysis of the trade route directions in comparison to the compass bearings marked next to them, shows that most of the route were drawn within the margin of error $\left(7.5^{\circ}\right)$ determined above (Fig. 12). All the routes through open seas and the routes drawn before the coast (either evidenced by the trunk routes drawn on the verso or the "first draft" of the alterations discussed above) were drawn with high accuracy. However, there are a number of routes marked in red in Fig. 12 that were significantly off course compared with the compass directions written next to the routes. The black lines are those found on the map and the red ones are re-drawn according to the compass bearings marked along the routes. These incorrect routes tend to be either near the coast or through a narrow strait. The trade route from Quanzhou (泉州) through Ryukyu to Hyogo (兵庫) became significantly off the compass directions by as much as $16^{\circ}$ once it approached the southern coast of Japan. Moreover the directions were not even self-consistent: a ren zi (壬子) direction is followed by a zi (子) direction which ought to indicate a steer towards a more easterly direction by $\sim 7.5^{\circ}$, but instead it was drawn towards a more westerly direction. It seems that the route was forced to be wrong by the constraints of the coastline, suggesting that this part of the route was put down after the coastline was drawn. The route along the south coast of Kalimantan to Banda is also badly off the compass directions. Had the route followed the compass bearing it would have gone over land eventually, suggesting that the drawing of the routes was constrained by the pre-defined coastline. The route just off the coast of the island of Java between Cirebon and Timor is also off the compass directions. The cartographer intended to draw the route first before the land (Fig. 11b discussed above) but seemed to have given up and drew the route to fit the coastline. Had the route been drawn to follow the compass bearing it would have missed Timor. Part of the route through the Strait of Malacca and the strait between the west coast of Sumatra and the line of islands to the west were also off the compass directions suggesting that in these parts the coastlines were drawn first before the routes. The route that was by far the most significantly off the compass direction $\left(>30^{\circ}\right.$ in the clockwise direction) was the route that runs between the north western exit of the Strait of Malacca and Calicut. The map clearly didn't have enough space to include Calicut and was thus forced to fit within the boundaries of the map. Where it is marked Calicut, it ought to have been the southern coast of Myanmar.

Various instances of other modifications have been found on the map. The most obvious was the Latin annotation made in the late seventeenth century after the map's arrival in the Bodleian Library. There are no other dated records of alterations. Figure 13 show that sections of the Great wall at the western end were modified using a white paint. The white paint seems to have been applied to erase the black and red lines, but the white was applied not only on the lines but also in the perpendicular direction where there were no lines (best illustrated in Fig. 13b). This is perhaps to mimic the depiction of the great wall in the map it copied from, where the wall was drawn with dashed lines (see Fig. 24 in [3]). Examples can be drawn from Chinese historical writings (even idioms still in current use) that suggests that orpiment is commonly used as a correction ink ${ }^{4}$ [36] presumably because paper were often dyed yellow by berberine (or Huangbo)

\footnotetext{
${ }^{4}$ Shen Kuo [36] explained that there were a number of methods to correct writing errors: (1) scrapping (which damages the paper); (2) glue a piece of paper over the writing (which has the disadvantage of potential detachment); (3) painting over with a white paint fen (粉) (which has the disadvantage of not having a high hiding power and multiple layers would be needed); (4) paint over with orpiment (which has the best hiding power and one layer would be sufficient). Finally he stated that this was the reason why ancients prefer qian huang (铅黄 or literally 'lead yellow') for painting over error. In the context, one would assume that this meant a lead white and orpiment mixture, but massicot is also commonly referred to as qian huang.
} 


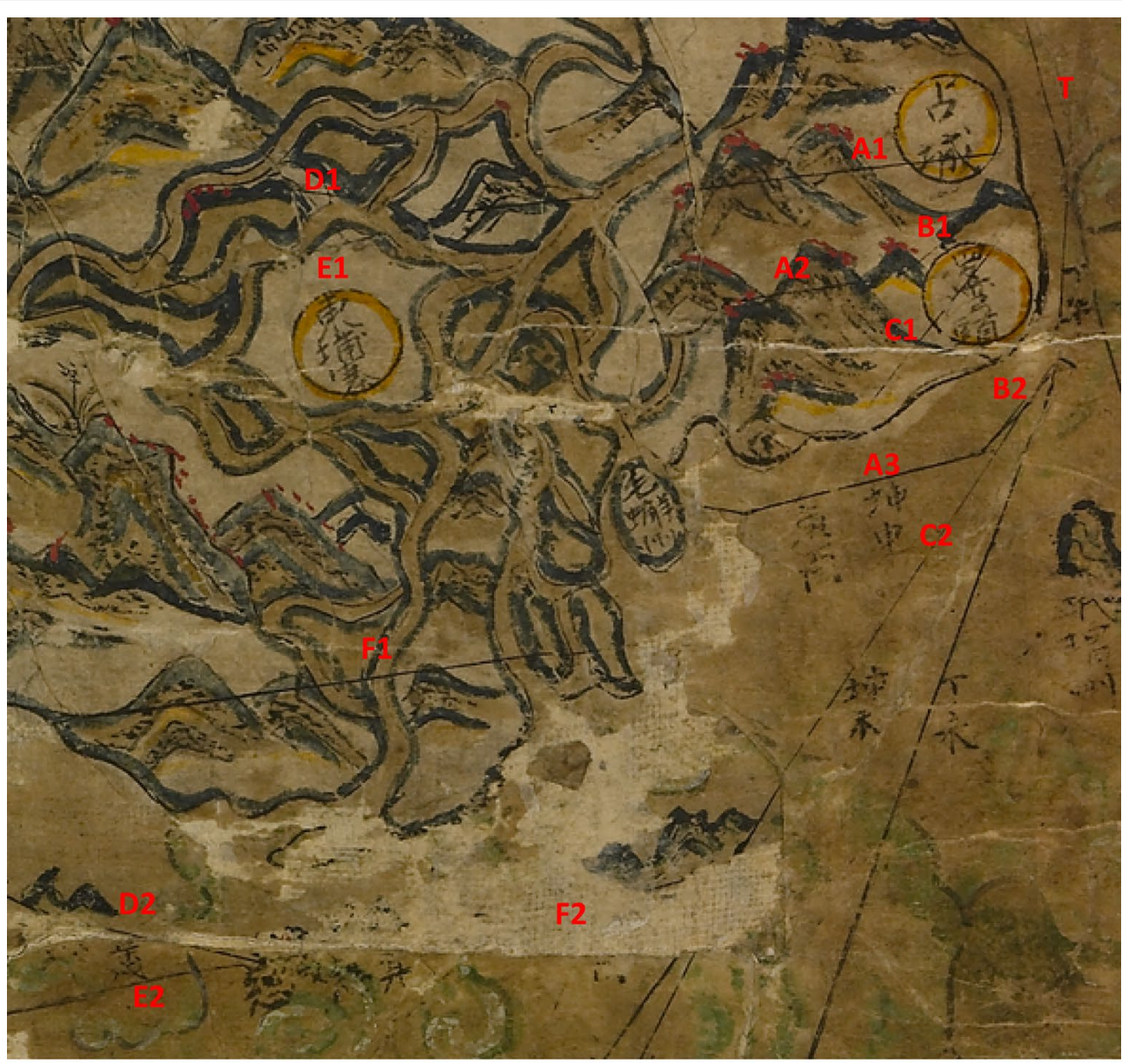

a

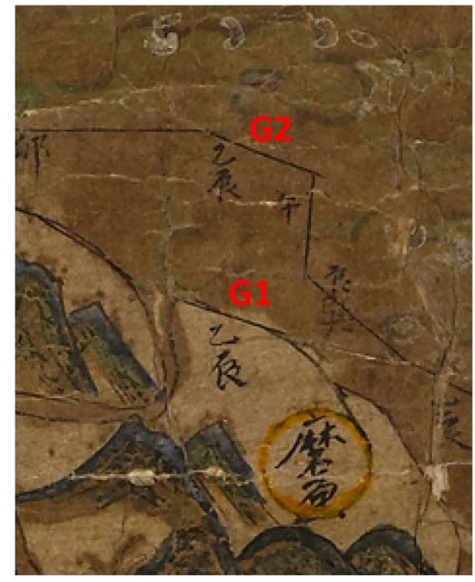

b

Fig. 11 Details from the Selden map (before 2011 conservation) showing multiple attempts at drawing the trade routes that were eventually covered by land near a southern Vietnam and Cambodia (to assist the reader the various routes are marked in red capital letters and the repeated attempts are marked in numbers, e.g. 'A1,' $A 2^{\prime}$ and ' $A 3^{\prime}$ are the 3 versions of the same route), note that the cartographer only annotated the final attempt with its compass directions); $\mathbf{b}$ Bali on Java (a short segment of the trade route on the edge of the coast with the compass bearing '乙辰' marked on the land was replicated off the coast above). The trunk route that correspond to those found on the back of the map is marked 'T'. @ The Bodleian Library, University of Oxford, MS Selden Supra 105 


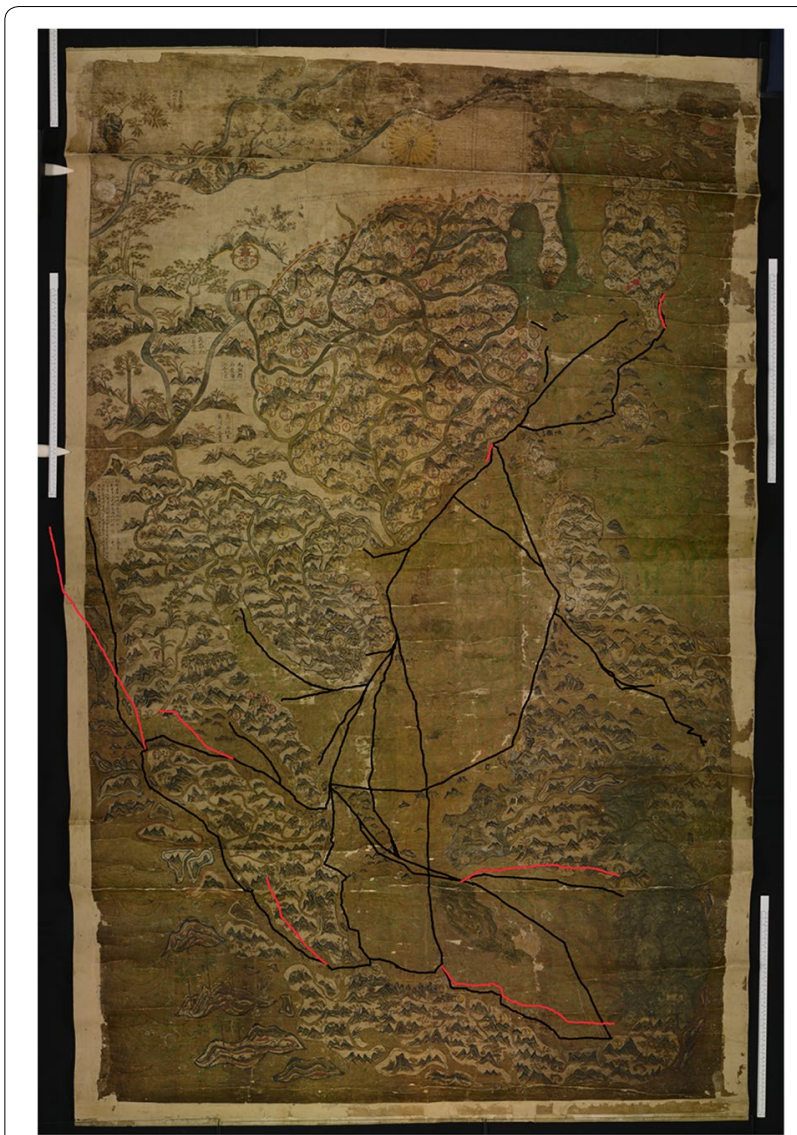

Fig. 12 The Selden map (before the 2011 conservation treatment) with the trade routes enhanced by thick black lines. Those that differ from the annotated compass directions by $>7.5^{\circ}$ are re-drawn in red in the correct directions according to the written compass bearings along the routes. The original colour image is @ The Bodleian Library, University of Oxford, MS Selden Supra 105

to repel insects [36-38]. Using a white paint was thought to be inferior in hiding power compared with orpiment. It is interesting to note that in Persian miniatures, lead white was used for corrections [25]. There is the possibility that orpiment was used but later faded due to the degradation process that produces $\mathrm{As}_{2} \mathrm{O}_{3}$ [23]. This can be easily verified by XRF. By comparing Fig. 13 a and c, one can see a mistake made in the tower on the wall at the top of the image where it was supposed to be painted in red; it was first painted with a black ink and then overpainted with vermilion. Similar mistakes were seen in the mountains on the right in Fig. 14 where it was painted-in with presumably a carbon black ink when it should have been painted with indigo and it was corrected later by applying a wash of indigo. It is not so obvious in the colour image but the near infrared image shows this clearly (Fig. 14b). Indigo is transparent while ink absorbs and is therefore black in the NIR.
There were also instances of major alterations on the map where what was originally painted as the sea was later changed into land and vice versa. Figure $15 \mathrm{a}, \mathrm{b}$ shows the area near Banjarmasin on the present day island of Kalimantan in Indonesia where the NIR image shows clearly the waves of the sea painted in a copper green that absorbs in the NIR and therefore dark. These have been painted over with a coastline, a place name (Banjarmasin) and hills. On the other hand, Fig. 15c, d reveals part of the dark green island-like form between the island of Kalimantan and Java that was originally drawn with a fine black boundary probably to indicate the coastline of an island but was later overpainted with dark green to merge with the sea. Similarly, Fig. 15e, f show the area between Banda and Timor to be heavily overpainted with dark green. The original fine black lines used on the land has been drawn over with thick dark line to indicate waves and painted over with a dark green paint.

The sea around Korea is unusually green compared to the rest of the map and questions were raised on whether that region had similarly been overpainted or not. However, it was found not to be the case as there were no inconsistent drawings revealed in the NIR image (image not shown here). It would be interesting to examine Taiwan in details as visual examination shows that there had been alterations both around Taiwan and Penghu island.

\section{Discussions}

There were major alterations made on the map suggesting that the map was executed in stages and at times by trial and error (Fig. 11). The trade route directions were drawn accurately according to their compass needle directions when they were through the open sea or when they were drawn before the coastlines were laid down. There were a number of instances where the trade routes had to be re-drawn to accommodate the landmass drawn in later (Fig. 11). These trade route directions were all accurately drawn, on the other hand, those trade routes that had to fit the coastline tend to be drawn off course compared with the compass directions marked (Fig. 12). The routes along the southern coast of China and along the east coast of the Philippines to Brunei were accurately drawn suggesting that they were drawn before the coast line. The south eastern part of the map is the most uncertain to the cartographer as major alternations were found in this area where land was overpainted into the sea and vice versa (Fig. 15). The routes along the coast in this part of the map were also off course which is not surprising given the changes made to the coastline. It seems that the cartographer was trying to match the land and the trade routes by trial and error. Part of the problem appeared to be the limited space on the map to fully 


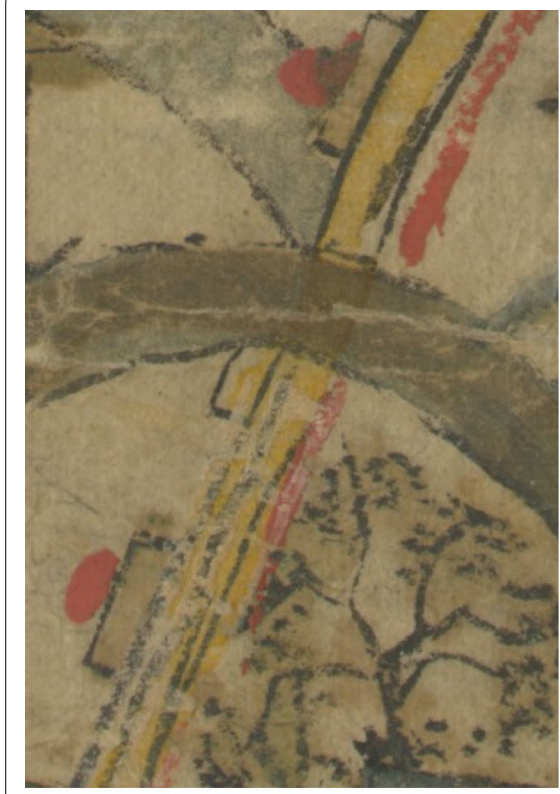

a

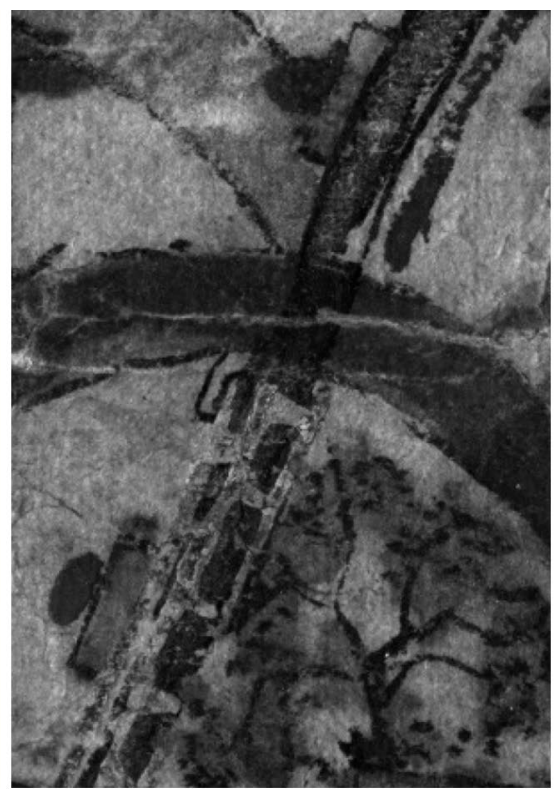

b

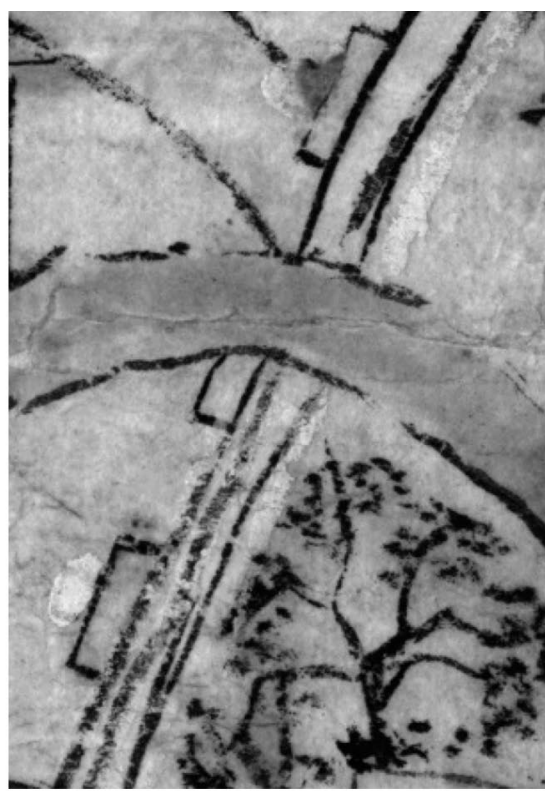

C

Fig. 13 a Colour image derived from the spectral image cube of'Area 19' on the Selden map in Fig. 1 near the Great Wall; b $450 \mathrm{~nm}$ image of the region showing alterations made to the wall; $\mathbf{c}$ near infrared $880 \mathrm{~nm}$ image of the same region

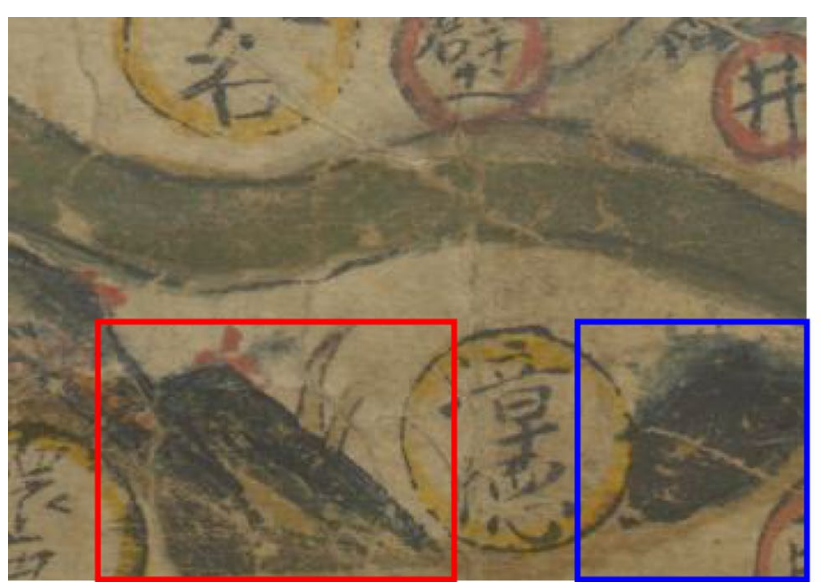

a

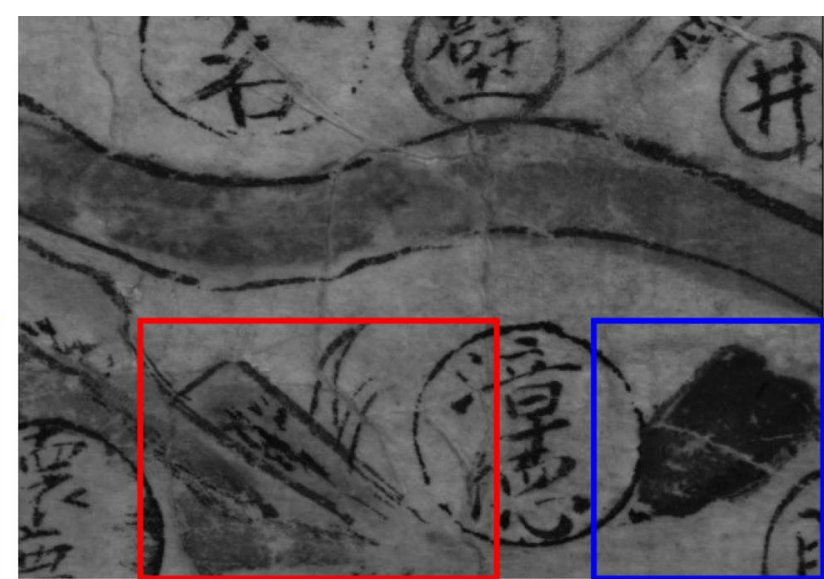

b

Fig. 14 a Coloured and $\mathbf{b}$ NIR ( $880 \mathrm{~nm}$ ) images of 'Area 17' on the Selden map. The mountain in the red square is transparent in the NIR but the mountain in the blue square is black in the NIR

accommodate the island of Java and the other part of the problem was uncertain knowledge of the eastern parts of that region. Similarly, on the western edge of the map, the route to Calicut was drawn incorrectly due to lack of space. It is interesting that the land around Vietnam, which was drawn too small compared to most of China, was originally planned to occupy an even smaller area (Fig. 11a). It is understandable that the routes in narrow straits such as the Malacca strait are difficult to be drawn with the correct directions. It is interesting to note that on the navigational charts of Admiral Zheng $\mathrm{He}$, the routes were not drawn according to their accompanying compass directions even though the written navigational directions were accurate. The Selden map cartographer did not have to draw the trade routes exactly according to the compass directions, but he clearly chose to do so 


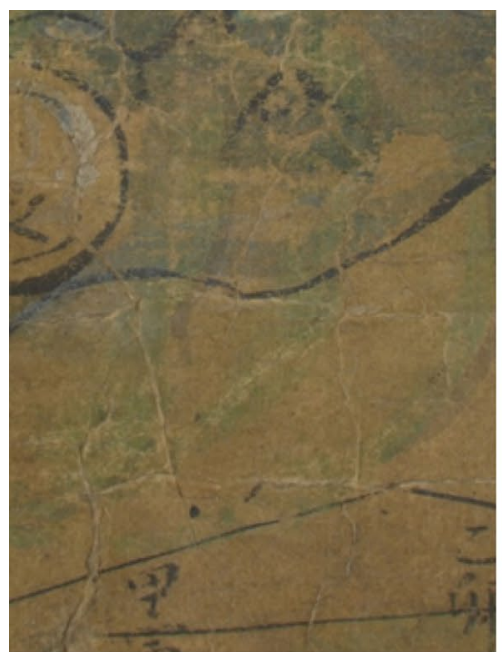

a

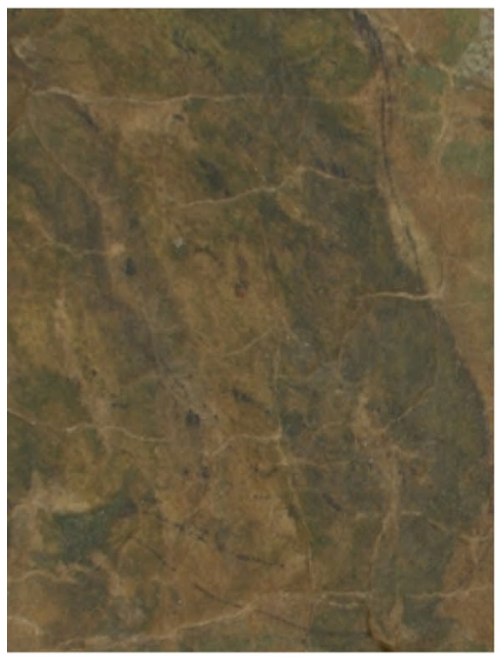

C

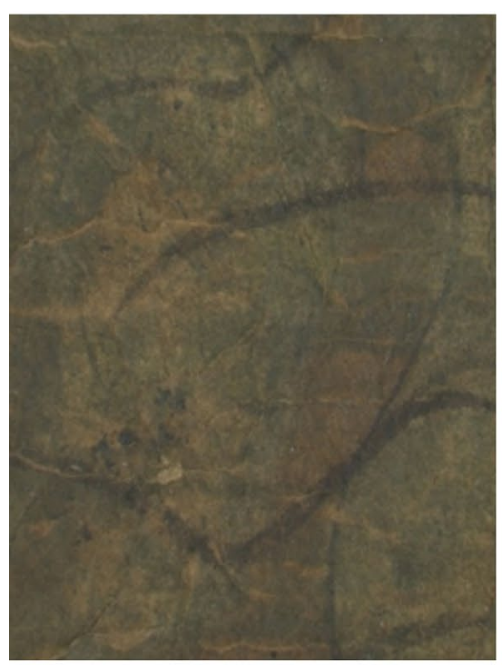

e

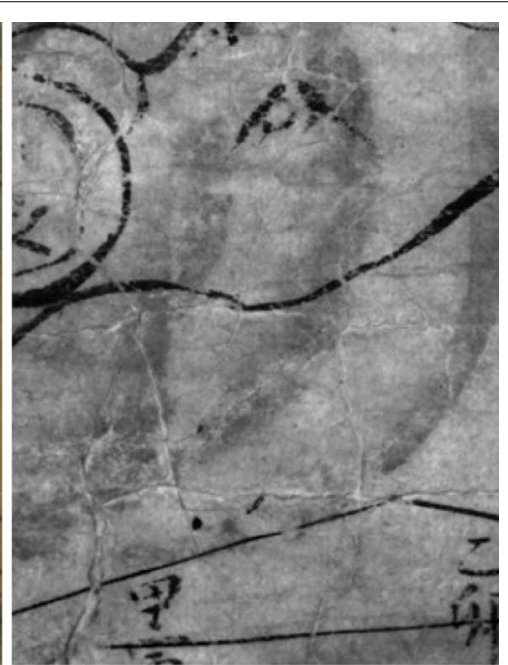

b

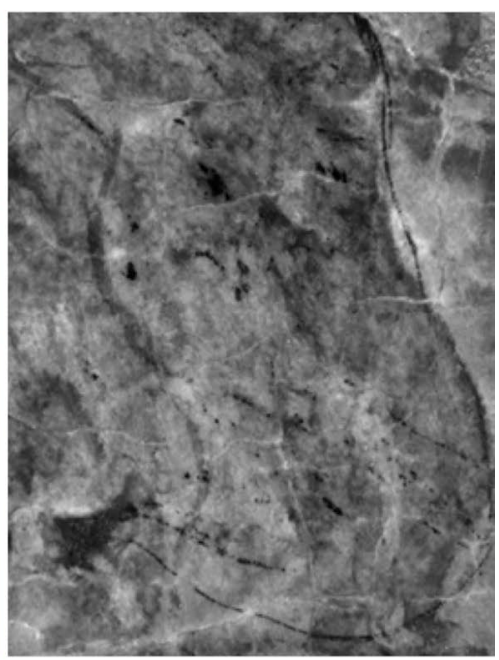

d

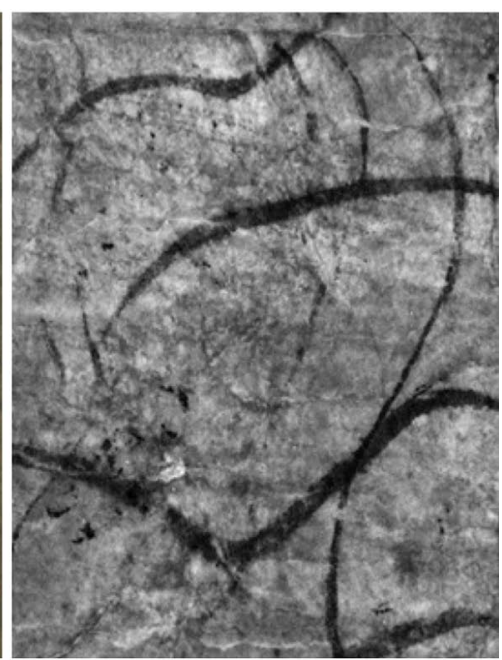

f 
(See figure on previous page.)

Fig. 15 a Colour image derived from the spectral image cube and $\mathbf{b} 880 \mathrm{~nm}$ NIR image of 'Area 31' of the Selden map near Banjarmasin. Land has been painted over what used to be the sea (waves painted in copper green show up dark in the NIR image). The bottom straight line seems to be a trade route that was drawn but later abandoned; c Colour image derived from the spectral image cube and $\mathbf{d} 880 \mathrm{~nm}$ NIR image of 'Area 34' on the Selden map in Fig. 1 between Banjarmasin on the island of Kalimantan and Cirebon on Java in Indonesia. Land painted in fine black drawings has been overpainted in green; e Colour image derived from the spectral image cube and $\mathbf{f} 880 \mathrm{~nm}$ NIR image of 'Area 35' on the Selden map in Fig. 1 near Banda in the Banda sea in Indonesia. The thin lines are more consistent with drawings on land while the thicker lines denote wave patterns in the sea. Land seems to have been overpainted to represent the sea

as the majority of the routes were drawn at least as accurately as he drew the compass rose. Brook suggested that the reason why some of the routes on the Selden map were off course was because of the difficulty in projecting a spherical earth to a flat sheet of paper [3]. However, even without the knowledge of a spherical earth, there is nothing stopping the cartographer drawing all the trade routes first, strictly according to the compass directions and his knowledge of the distances (presumably derived from travel time), before drawing in the landmass. All he needed to do then was to distort the landmass to fit the routes and by doing so he would have naturally produced a map roughly similar to the one that followed the Mercator projection. In actual fact that is more or less what he did as only a handful of routes were drawn after the landmass was drawn. This is probably the reason why the Selden map roughly resembles our modern map of the region.

There are two routes on the map that did not have accompanying compass directions marked on them, the route from Manila to Ternate island and the route along the East China coast towards the north from Quanzhou, suggesting perhaps the map was not fully completed.

All the trade routes start from Quanzhou and the compass needle directions point in the outward journey directions. In addition, the China part of the map was closely copied from the one in the popular Fujianese encyclopedia of 1599 , even down to the use of the unorthodox version of the character for the word 'country' (国 instead of 國). ${ }^{5}$ It seems most likely that the cartographer has a close connection to Fujian which would not be surprising since the two Fujianese ports were the most active Chinese ports for overseas trade at the time. Most of the Chinese merchants, sailors or pirates traveling on the sea routes or residing at one of the ports outside China in this period would have been Fujianese from these two ports. Therefore, the cartographer/painter of the Selden map is most likely to be from Fujian, but there remains the question of where it was made.

It has been pointed out that the inclusion of the compass rose and the scale bar on the Selden map indicates European influence. The identification of gum Arabic but

5 国 not to be confused with the simplified character 国 for 'country'. not animal glue is further evidence of its unusual origin. While the broad appearance of the map and the painting style appears to be Chinese or East Asian, the use of gum Arabic (and not animal glue) as a binding medium in paintings from China of this period is unheard of and equally the combination of orpiment, indigo and a basic copper chloride to form a green colour in a painting from Ming China has not been reported so far. In the early seventeenth century, gum Arabic is the common binding medium used for paper-based works of art in Europe [24] and in South and West Asia, e.g. Persian or IndoPersian illuminated manuscripts $[25,26]$. It is interesting that in the Indo-Persian tradition there was a practice of adding sheep milk to gum Arabic to improve the texture of a paint [26]. It is worth noting that a trace amount of casein was detected in the HPLC-MS analysis of a fragment from the Selden map. The combination of orpiment and indigo to create a green colour is common in European and Islamic manuscripts of this time [39-41], but in China the common mixture for a green is indigo and gamboge [23, 28, 42]. While orpiment is mentioned as a source of pigment in Chinese historical sources, it is rarely detected on paper-based paintings from China except for some scroll paintings from Dunhuang on the Silk Road [23]. However, there is at least one alternative explanations for the detection of orpiment. It is known from historical sources that orpiment was sometimes used to protect the paper substrate from insect attacks $[23,37]$, though material examples of such treatment is rare. It is more common to find paper treated with berberine (or Huangbo) giving it a yellow appearance [3638]. In a large survey conducted by the Freer Gallery, orpiment was not found on any of the Japanese Ukiyoe paintings until after the seventeenth century [43]. In China orpiment is also used to make corrections owing to its good hiding power, but in the Persian tradition lead white is more commonly used for corrections [25]. The corrections on the Selden map (Fig. 13) were made with a white paint. While basic copper chlorides such as atacamite are known to have been used on wall paintings and as architectural paint in China [23, 29, 30], its use on paper-based paintings from China is rarely reported except for silk paintings found in Dunhuang along the Silk Road [23]. It is worth noting that during the time 
of the Ming, Dunhuang was outside the Chinese border. Atacamite and its isomers are not usually found on paper-based paintings in the western European tradition [31]. However, atacamite seems to be commonly used in Persian or Indo-Persian manuscripts of this period [25, 39]. Basic copper chlorides were not found on Japanese Ukiyo-e paintings before the eighteenth century in the Freer Gallery survey of $\sim 500$ such paintings from the late sixteenth to nineteenth century [43]. Overall the binding medium and pigment use appear to be more consistent with a Persian or Indo-Persian tradition than that of Chinese, Japanese or European in this period.

A number of conjectures has been proposed for the origin of the Selden map of China. Some scholars thought that the map was made in the neighbouring port cities of Quanzhou (泉州) or Zhangzhou (漳州) in southern Fujian by a local scholar or by a Sinicized Arab/Persian merchant settled in Quanzhou since there was a sizable Arab/Persian community in Quanzhou at the time [8], others thought it was made by a Chinese (Fujianese) in Manila [1] or in Banten in West Java [3]. These hypotheses will be examined in the following section in view of the new evidences from the analyses above.

It is unlikely for a Fujianese cartographer/painter living in China to paint the map using gum Arabic rather than the usual animal glue even if he had seen foreign maps and borrowed the idea of painting a compass rose on the map. A non-Chinese living in China sinicized to the extent of producing such a Chinese style painting might more easily have used animal glue than gum Arabic which might have been difficult to source.

There are more place names marked in Japan than many other areas outside of China, however, past studies have concluded that the map was unlikely to have been made in Japan for two reasons. Firstly, apart from the Kyushu island, the rest of Japan is distorted and incomplete, and secondly, Japanese place names have not always been labelled using their proper Chinese characters [1-4]. Rather, the characters on the map appear to be transliterated from the Portuguese pronunciations, which strongly suggests that the cartographer's knowledge of Japan came second hand and from the Europeans. These odd names are usually associated with southern Japanese trading ports such as Nagasaki which was established as a global trading port by the Portuguese. Here we will explore this hypothesis in light of the analytical results on the materials. There is no suggestion of gum Arabic being used as a binding medium for paper-based paintings even in the Jesuit schools in Japan at this time [44]. As early as the 1580s, the Jesuit seminary in Nagasaki was teaching the Japanese western music and painting techniques to facilitate the spread of Christianity until the early seventeenth century when Christianity was banned. Chinese
Christian converts from Macau were sometimes sent to the Jesuit schools in Japan to learn western religious painting techniques. Two such students were responsible for painting Matteo Ricci's portrait at his death bed in Beijing in 1610 [45]. Analysis of a western style map of the world as well as another Christian painting from Japan of the late sixteenth and early seventeenth century, both on paper substrates, found that they were painted in both animal glue and oil [43]. It is interesting that the Christian missionary influenced Japanese paintings combined the local binding medium animal glue with the common European binding medium normally used on easel paintings rather than paper-based works of art. Given that in this period the common binding medium for paper-based paintings in Europe was gum Arabic, it is odd that oil was used instead. Perhaps the Japanese artists were mainly taught to paint Christian themed easel paintings by the Europeans but not the illuminated manuscripts. Neither oil nor animal glue were found in the case of the Selden map. In addition, the use of orpiment and basic copper chloride were not known for paintings from Japan of this period [23, 43]. It seems that the new material evidence does not support the Japanese origin either.

Another suggestion is that the author of the map is a Fujianese living in Manila, since there was at the time a sizable Chinese community based in Manila and the reference to the Spanish as huaren (化人) was specific to the Chinese community living in the Philippines [7]. Batchelor $[1,2]$ also proposed that the map is likely to have been made in Manila and captured on route to Japan by the East Indian Company's ship Elizabeth. The coast near Manila was annotated in detail, the Midoro Strait and Apo Reef were marked as gateway to a route towards Ternate and Tidore. The presence of the Spanish was indicated on the map on the east coast of the Philippines, probably referring to the Manila-Acapulco Galleon trade started in 1565. Manila at the turn of the seventeenth century was at the centre of globalisation with the Chinese coming from the north, the Persians, Arabs, Indians, English and Dutch from the west and the Spanish arriving with their galleons of silver from Mexico in the east. It is well documented that prior to the Spanish settlement in Manila in 1571, there were only 150 Chinese living there but by 1603 the Chinese community numbered $\sim 30,000$ because of the trade with the Spanish [46]. It was noted in 1589 by the Bishop of Manila that there were all kinds of craftsman including painters amongst the Chinese. Painting materials were known to have been imported from China. Similar to Japan, the Jesuits in the Philippines were also teaching local painters, who were predominantly Chinese painters, the art of European religious painting techniques starting from the early 
1580s [45-47]. At present there is very little scientific data available for such paintings to compare with, but if the situation is similar to what happened in Japan, then the binding medium might have been a mixture of animal glue and oil. We must also consider that before the arrival of the Spanish, Islam had already spread to the Philippines. Muslim merchants from South and West Asia were known to frequent the ports and some settled there. However, it seems that painting as a representational art form was unknown in the Philippines before the Spanish conquest [46]. Paintings in the form of Islamic illuminated manuscripts are only known from the southern Philippines from a much later period [48]. It would, therefore, seem more natural for the Chinese painters in Manila to follow the traditional Chinese way of painting unless they were recruited by the Christian missionary to paint. However, as mentioned above, the binders and pigment use are more consistent with those from the Islamic world than the European or the Chinese. Another observation is that the route from Manila to Ternate was marked in detail with all the zigzags that end up in both the Spanish and Dutch controlled areas suggesting that the cartographer's knowledge of this route was very detailed. It is curious that there were no compass directions marked on this route. The only other route that did not have compass direction marked was the one along the East China coast north from Quanzhou. One might argue that if the cartographer was a Fujianese living in Manila, then he might be familiar with these two routes and therefore found it less urgent or important to mark the exact directions on them. However, it was noted by Gong [7] that the relative positions of the Dutch and Spanish on the Ternate Island were incorrect and the relative positions of some of the cities along the east coast of China were also incorrect, suggesting perhaps the cartographer was unfamiliar with these parts of the world. Brook noted also that southern parts of the Philippines were not as accurately drawn as many other parts of the map [3]. Further study of the art history of the Philippines and scientific analysis of paintings from the Philippines in the sixteenth and early seventeenth century are needed before we can make conclusive statements about this hypothesis.

Brook suggested that the map was made in West Java and taken in $\sim 1609$ by John Saris, a captain of the East India Company [3]. Qian agreed with this suggestion and thought Banten, an important port in the early seventeenth century, was most likely, since Jakarta only overshadowed it after the Dutch settlement in 1619 [8]. The Banten Sultanate was founded in the sixteenth century and as a result Islam spread in Banten. Chinese traders are recorded to have frequented Banten since at least the thirteenth century and the large seventeenth century
Chinese cemeteries in Banten testifies the presence of the Chinese during this period [8]. In contrast with the situation in Japan and the Philippines, Europeans were not well established in Banten in this period. For the Chinese cartographer to have adopted the new painting material and technique, there needs to be a well-established IndoPersian painting tradition in Banten. Again we look to any potential borrowings from illuminated manuscripts. A comprehensive art historical study through visual analysis of Islamic manuscripts from Banten, found the manuscripts to be unusual in the Malaya world in that they were mostly not illuminated $[48,49]$. The three that were illuminated were also unusual in their colour scheme. It was concluded that there was a lack of tradition in manuscript illumination in Banten compared with other centres in the Malaya world. The surviving manuscripts are mostly from the eighteenth to the nineteenth century similar to other places in South East Asia.

Finally we suggest a new alternative that is the map was made in Aceh by a Fujianese, possibly a Muslim in close contact with the Islamic world. Because of its geographic location, Aceh was frequented by Indian, Arab, Chinese and European traders. Aceh was the first region in South East Asia to be converted to Islam, dating back to at least the thirteenth century. The Sultanate of Aceh became one of the most powerful states in South East Asia after the Portuguese captured Malacca in 1511 making Malacca less attractive as a trading post for Islamic traders and thus benefiting Aceh in the competition for trade. Aceh is the most westerly port on the map in South East Asia and therefore closer to the Islamic world and have more access to the painting materials and techniques adopted. If we take the magnetic declination shown by the compass rose to correspond to that at the location where the map was made, then Aceh is the only port marked on the Selden map to have a magnetic declination close to $6^{\circ}-8^{\circ}$ west in the early seventeenth century. In addition, Aceh is also one of the only six ports marked with a red circle. The six ports are Aceh in Sumatra, Nakhon, Phatthalung, Patani and Kedah on the Malay peninsula across the strait but safely away from the Portuguese in Malacca, and Hue in central Vietnam. There is a historical link between central/southern Vietnam and Aceh. People from central/south Vietnam fled to Aceh after the collapse of the Champa Kingdom in late fifteenth century. These six ports are clearly marked to be special and may indicate the main trading network of the map owner. Aceh in the early seventeenth century was frequented by the Persian, Arab, Indian, Chinese, Dutch and English traders. It rivalled the Portuguese controlled Malacca. The proximity to India and Persia and the long history of Islamic influence makes it more likely that the cartographer would have had access to the same painting 
materials as those in the Islamic world and learnt how to paint with these materials. One of the earliest surviving illuminated document in the Malaya world was a royal document from the Sultan of Aceh to King James I of England in 1615. An art historical study of a large corpus of Acehnese illuminated manuscripts (the earliest surviving example known was from the eighteenth century) found the style to be most distinct and coherent compared to other regions in the Islamic world of South East Asia suggesting a well-established tradition of illumination $[48,50]$. This is a necessary environment for the fusion of painting materials and techniques seen in the Selden map. In addition, any English or Dutch ship going back to Europe from South East Asia would have to pass by Aceh either from the east or west coast of Sumatra and thus giving them the chance to obtain the map. It is interesting that while the activities of the Spanish and the Dutch were marked on the map, there was no mention of the Portuguese anywhere on the map. Perhaps the Portuguese had been there long enough not to be considered necessary to mark on the map. Further historical research is necessary to test this new hypothesis.

\section{Conclusions and future work}

Scientific examination of the Selden map using mostly non-invasive analytical techniques found the palette to consist of indigo in the blue regions, the dull red areas and the green areas, vermilion in the red areas, a copper green (most likely atacamite or one of its three isomers and possibly malachite) in the green regions, most likely gamboge in the yellow regions and orpiment in the green regions. A mixture of indigo with orpiment (rather than gamboge) to make a green colour is unusual for a painting from China in this period. Similarly, if confirmed, the detection of basic copper chloride such as atacamite on a paper-based Chinese painting may be somewhat unusual. Basic copper chloride is not usually used on paper-based paintings from China proper or western Europe but common for South and West Asian illuminated manuscripts. The most surprising result is the identification of gum Arabic, a trace amount of casein and non-detection of animal glue as the binding medium. This is highly unusual for a Chinese style painting where animal glue is usually expected to be the binding medium. These results suggest that the painting is unusual not only in the depiction of a compass rose on a Chinese style map, but also in the binding medium and some of the pigments and pigment mixtures used. The scientific evidence suggests a fusion between Chinese and South and West Asian painting materials and techniques.

Only spectral imaging has so far been applied directly to the map. All the other techniques were applied to a few green fragments. However, XRF, a portable Raman spectrometer, OCT, FTIR with a reflection module and VIS-NIR fibre optic reflectance spectroscopy can all be applied directly on the map to fully exploit the advantages of non-invasive investigation. The advantage of non-invasive investigation is not just to reduce damage but also to be able to examine anywhere on the map rather than being restricted to a few spots. Future applications of the suite of non-invasive techniques directly on the map will allow the identification of the full palette and confirm some of the results presented here.

Detailed examination of the various spectral bands of the spectral images found a number of instances where the author of the map had made alterations. Some of the alterations were stylistic or unintentional mistakes, others were major alterations as the cartographer's knowledge of a certain area changed. The most interesting alterations were those of the trade routes giving direct evidence that many of the routes were laid down before the land was drawn in. An analysis of the directions of the trade routes compared with their compass bearings showed while most of the routes were accurately drawn according to the accompanying compass directions, a number of routes were drawn off course relative to the compass directions suggesting that some of these were drawn after the coastlines were painted. The cartographer clearly did not plan the full map from the beginning which was why he had to redraw some of the routes many times and he was running out of space at the southern and western parts of the map forcing the trade routes to be off the compass directions. The drawings were executed first before the coloured paints were applied. Two trade routes were drawn without their corresponding compass directions indicating that the map was perhaps unfinished.

The various hypotheses of the map's origin suggested by past historical research were examined in view of the new evidences. While the results from the scientific analysis cannot definitely rule out any of the possibilities, the South and West Asian influence as shown in the binding medium and pigment use makes a location towards the more western ports on the map with strong Islamic influence more likely. Finally we propose an alternative origin for the map in Aceh at the north-west end of Sumatra where it opens out to the Indian Ocean. It is the most westerly port in South East Asia marked on the map and it has the longest history of the presence of Islam in South East Asia as well as a long history of Chinese contact. Aceh is the port on the map to have a magnetic declination in the early seventeenth century closest to that indicated by the tilt of the compass rose. In addition, it is one of the only six ports on the map marked with a red circle. These ports may be part of an important trading network headed by the map's owner. Further historical investigation is necessary to test this hypothesis. Art historical 
analysis of illuminated manuscripts from Aceh from the eighteenth to nineteenth century showed that it had the most coherent and established tradition of manuscript illumination in the Malaya world. It is unfortunate that few illuminated documents from South East Asia of the early seventeenth century survived to allow a comprehensive study of the painting materials and techniques in paper-based works of art from different regions of South East Asia to compare with the Selden map. Finally, many unorthodox Chinese characters have been used on the map and a systematic study of the use of these characters may also shed light on the cartographer's background.

\begin{abstract}
Authors' contributions
SK analysed the spectral imaging data, collected and analysed the VIS/NIR fibre optic reflectance spectroscopy, FTIR and the SEM/EDX, drafted the preliminary version of the results section, liaised and organised measurements with other colleagues at NTU in 2015/16. SN initiated the collaboration, liaised between the Bodleian Library and the other authors and conducted preliminary FTIR-ATR, XRD, SEM-EDX analysis on the fragments in 2009. CC, AM and $\mathrm{DB}$ were responsible for the mass spectrometry liquid chromatography analysis and drafted the relevant sections of the manuscript. LB was responsible for the Raman and XRF analysis on the fragments. CSC was responsible for the UHR-OCT images and analysed the trade routes as compared with their compass bearings. HL coordinated the overall project, wrote the code for pigment identification, conducted the preliminary analysis of the spectral imaging data, conducted the research on the historical sources and drafted the manuscript. All authors commented on the draft and approved the final manuscript. All authors read and approved the final manuscript.
\end{abstract}

\section{Author details}

${ }^{1}$ School of Science \& Technology, Nottingham Trent University, Nottingham NG1 1 8NS, UK. ${ }^{2}$ Conservation and Collection Care, Bodleian Library, University of Oxford, Oxford OX1 3BG, UK. ${ }^{3}$ Research Laboratory for Archaeology and the History of Art, University of Oxford, Oxford OX1 3QY, UK. ${ }^{4}$ John van Geest Cancer Research Centre, Nottingham Trent University, Nottingham NG1 1 8NS, UK. ${ }^{5}$ Science Section, Conservation Department, Victoria and Albert Museum, South Kensington, London SW7 2RL, UK.

\section{Acknowledgements}

We are grateful to the following colleagues for assistance: Simon Godber, David Parker, Gordon Arnold of Nottingham Trent University (NTU) for technical assistance, Kafing Keita of NTU for assisting with the in situ imaging of the map at the Bodleian Library using the PRISMS spectral imager, John Wallis, Gareth Cave, Quentin Hanley and David Kilgour of NTU, Marinita Stiglitz and Robert Minte of the Bodleian Library, Dai Nianzu of Chinese Academy of Natural Sciences, Amir Hossein Karimy of the University of Isfahan and Parviz Holakooei of the Metropolitan Museum of Art for useful discussions. HL is grateful to David Howell for hospitality during the visit. Funding from the Bodleian Library for the in situ imaging campaign is gratefully acknowledged. Funding from UK EPSRC Grant (EP/E016227/1) is acknowledged for the development of the PRISMS spectral imaging system, and the UK AHRC and EPSRC Science \& Heritage Program (AH/H032665/1) is acknowledged for the development of the UHR-OCT.

\section{Competing interests}

The authors declare that they have no competing interests.

Received: 19 April 2016 Accepted: 26 July 2016

Published online: 02 September 2016

\section{References}

1. Batchelor R. The selden map rediscovered: a Chinese map of East Asian shipping routes, c.1619. Imago Mundi. 2013;65:37-63.
2. Batchelor R. The Selden map and the making of a global city, 1549-1689. London: University of Chicago Press; 2014.

3. Brook T. Mr Selden's map of China. London: Profile Books; 2013.

4. Nie H. The Selden map of china - a new understanding of the ming dynasty. Bodleian Library: University of Oxford; 2014.

5. Davies $\mathrm{S}$. The construction of the Selden map: some conjectures. Imago Mundi. 2013;65:97-105.

6. Chen J. Brief analysis of the composition, date, features, names and route names of places of the Selden Map of China (明末疆里及漳泉航海通交 圖: 编绘时间, 特色及海外交通地名略析). Hai jiao shi yan jiu (海交史 研究). 2011:2:52-66.

7. Gong Y. A ming dynasty nautical chart newly discovered overseas (國外新近發現的一幅明代航海圖). Li shi yan jiu (歷史研究). 2012;3:156-60.

8. Qian J. A mid-ming watercolour navigation map recently discovered at Oxford University (一幅新近發現的明朝中葉彩繪航海). Hai jiao shi yan jiu (海交史研究). 2011;1:1-7.

9. Jiao T. Mapping ming china's maritime world. 1st ed. Hong Kong Maritime Museum: Chung Hwa Book Co.; 2015.

10. Needham J, Wang L. Science and civilisation in China: mathematics and the science of the heavens and the earth. Cambridge: Cambridge University Press; 1959

11. Smith R. Mapping China and managing the world: culture, cartography and cosmology in late imperial times (Asia's Transformations/Critical Asian Scholarship). 1st ed. London: Routledge; 2012.

12. Mao Yuanyi (茅元儀). Treatise on Armament technology (《武備志》卷 二百四十), c.1621. https://www.loc.gov/item/2004633695/. Accessed 1 Aug 2016.

13. Minte R, Stiglitz M, Sugiyama K, Bernard M. From Quanzhou, China to Oxford, UK: an account of the Selden map of China and its conservation. Stud Conserv. 2014;59:S115-8.

14. Kogou S, Lucian A, Bellesia S, Burgio L, Bailey K, Brooks C. A holistic multimodal approach to the non-invasive analysis of watercolour paintings. Appl Phys A. 2015;121:999-1014.

15. Liang H, Keita K, Vajzovic T, Zhang Q. PRISMS: remote high resolution in situ multispectral imaging of wall paintings, ICOM-CC 15th triennial conference preprints. Delhi: Allied publishing; 2008. p. 353-8.

16. Liang H, Lucian A, Lange R, Cheung C, Su B. Remote spectral imaging with simultaneous extraction of 3D topography for historical wall paintings. ISPRS J Photogramm Remote Sens. 2014;95:13-22.

17. Liang H. Advances in multispectral and hyperspectral imaging for archaeology and art conservation. Appl Phys A. 2012;106:309-23.

18. Vandenabeele P, Edwards $H$, Jehlicka J. The role of mobile instrumentation in novel applications of Raman spectroscopy: archaeometry, geosciences, and forensics. Chem Soc Rev. 2014;43:2628-49.

19. Cheung C, Spring M, Liang H. Ultra-high resolution Fourier domain optical coherence tomography for old master paintings. Opt Express. 2015;23:10145-57.

20. Chiari G, Sarrazin, P (2008) Portable non-invasive XRD/XRF instrument: a new way of looking at objects surface, In: Proceedings of ART2008, 2008. http://www.ndt.net/article/art2008/papers/231Chiari-Sarrazin. pdf. Accessed 1 Aug 2016.

21. Kirby D, Phillips K, Khandekar N. Implementation of MALDI mass fingerprinting in a museum laboratory for the identification of proteins in works of art. 2011. http://www.ndt.net/article/art2011/papers/KIRBY\%20 -\%20M\%201.pdf. Accessed 1 Aug 2016.

22. Yu Feian (于非闇), Painting Colors: Studies of their Preparation and Application in Traditional and Modern Times (中國畫的研究), J. Silbergeld and A. McNair, trans. Hong Kong, London: Hong Kong University Press, University of Washington Press; 1988.

23. Winter J. East Asian paintings - materials, structures and deterioration mechanisms. London: Archetype Publications; 2008.

24. Kroustallis $\mathrm{S}$. Binding media in medieval manuscript illumination: a source research. Revista de Historia da Arte. 2011;1(Serie W):113-25.

25. Purinton N, Watters M. A study of the materials used by medieval persian painters. JAIC. 1991;30(2):125-44.

26. Chowdry A. The studio practice of painters of the mughal ateliers. In: Contributions to the symposium on the care and conservation of middle eastern manuscripts, Australia: The University of Melbourne; 2007, p. 36-49.

27. Kubelka P. New contributions to the optics of intensely light-scattering materials. Part I. J Opt Soc Am. 1948;38:448-57. 
28. Wang Gai, Wang Shi, Wang Nie (王概, 王萻, 王臬). The mustard seed garden manual of painting. Translation of Chieh tzu yuan hua chuan ( 芥子園畫譜), 1679-1701. Sze, M. trans., New York, Princeton: Bollingen Foundation, Princeton University Press, 1956

29. Lei Y. Copper trihydroxychlorides as pigments in China. Stud Conserv. 2012;57:106-11.

30. Egel E, Simon S. Investigation of the painting materials in Zhongshan Grottoes (Shaanxi, China). Heritage Science. 2013;1:29.

31. Scott D. A review of copper chlorides and related salts in bronze corrosion and as painting pigments. Stud Conserv. 2000;45(1):39-53.

32. Jackson A, Jonkers A, Walker M. Four centuries of geomagnetic secular variation from historical records. Phil Trans R Soc Lond A. 2000;358:957-90.

33. Dai N. Zhu Zaiyu - The Science and Art Superstar of the Ming Dynasty ( 朱载䏴一明代的科学和艺术巨星), Ren ming chu ban she (人民出版社); 1986.

34. Zhu Zaiyu (朱载堉), The pitch-pipes and their calendrical concordances, ( 《律曆融通》卷四 黄钟历议 正方), c.1581. http://ctext.org/library.pl?i $\mathrm{f}=$ gb\&file=75864\&page=68\&remap=gb. Accessed 1 Aug 2016 .

35. Needham J, Wang L, Robinson K. Science and civilisation in China, physics and physical technology, part l: physics. Cambridge: Cambridge University Press; 1962

36. Shen Kuo (沈括), Dream Pool Essays (《夢溪筆談》卷二十四), c.1090. http://ctext.org/library.pl?if=gb\&file=5128\&by_title=\%E5\%A4\%A2\%E6 \%BA\%AA\%E7\%AD\%86\%E8\%AB\%87\&page=25\&remap=gb. Accessed 1 Aug 2016.

37. Jia Sixie (贾思茜), Essential skills to benefit the people（《齊民要術》卷 三), c.544. http://ctext.org/library.pl?if=gb\&file=54251\&page=159\&rema $\mathrm{p}=\mathrm{gb}$. Accessed 1 Aug 2016.

38. Gibbs P, Seddon K. Berberine and huangbo: ancient colorants and dyes. In: The British library studies in conservation sciences 2. London: The British Library; 1998.

39. Muralha V, Burgio L, Clark R. Raman spectroscopy analysis of pigments on 16-17th c. Persian manuscripts. Spectrochim Acta Part A Mol Biomol Spectrosc. 2012;92:21-2841

40. Anselmi C, Ricciardi P, Buti D, Romani A, Moretti P, Beers K, Brunetti B, Miliani C, Sgamellotti A. MOLAB ${ }^{\circledR}$ meets Persia: Non-invasive study of a sixteenth-century illuminated manuscript. Stud Conserv. 2015;60(Supplement 1):S185-92.
41. Tanevska V, Nastova I, Minceva-Sukarova B, Grupce O, Ozcatal M, Kavcic M, Jakovlevska-Spirovska Z. Spectroscopic analysis of pigments and inks in manuscripts: II. Islamic illuminated manuscripts (16th-eighteenth century). Vib Spectrosc. 2014;73:127-37.

42. Giaccai J. and Winter J. Chinese painting colors: history and reality. In scientific research on the pictorial arts of Asia. In: Proceedings of the second forbes symposium at the freer gallery of art. London: Archetype Publications Ltd; 2005, p. 99-108.

43. Fitzhugh $\mathrm{E}$. A database of pigments on Japanese Ukiyo-e Paintings in the freer gallery of art, in studies using scientific methods-pigments in later Japanese paintings. Freer gallery of art occasional papers, New Series Vol I, Smithsonian Institute; 2003, p. 1-56.

44. Oka Y, Miura S, Hayakawa Y, Miyakoshi T. Scientific analysis used in the treatment of the map of the world and famous cities screens and resulting new perspectives on the paintings. In scientific research on the pictorial arts of Asia, In: Proceedings of the second forbes symposium at the freer gallery of art. London: Archetype Publications Ltd; 2005, p. 16-20.

45. Mungello D. The great encounter of China and the West, 1500-1800. 4th ed. Lanham: Rowman \& Littlefield; 2013.

46. Pilar S. Philippine painting: the early Chinese heritage. Arts of Asia. 1994;24:62-72.

47. Tse N. Artistic practices of the Bohol school of painting: an analytical and archival study of nineteenth-century panel paintings in the Philippines. In Scientific Research on the Pictorial Arts of Asia, In: Proceedings of the Second Forbes Symposium at the Freer Gallery of Art. London: Archetype Publications Ltd; 2005, p. 16-20.

48. Gallop A. Islamic manuscript art of Southeast Asia. In: Bennett J, editor. Crescent moon: Islamic art and civilisation in Southeast Asia. Australia: Art Gallery of South Australia; 2005. p. 158-83.

49. Gallop A. The art of the Qur'an in Banten: calligraphy and illumination. Archipel. 2006;72:95-156.

50. Gallop A. An acehnese style of manuscript illumination. Archipel. 2004:70:193-240

\section{Submit your manuscript to a SpringerOpen ${ }^{\circ}$ journal and benefit from:}

- Convenient online submission

- Rigorous peer review

- Immediate publication on acceptance

- Open access: articles freely available online

- High visibility within the field

- Retaining the copyright to your article

Submit your next manuscript at $\boldsymbol{\nabla}$ springeropen.com 